\title{
O CAMINHO DAS PEDRAS
}

\author{
Pedro Angelo Almeida Abreu (*)
}

\begin{abstract}
Application of modern geological concepts lead to the identification of different processes involved in the geodynamic evolution of the southern Serra do Espinhaço, Minas Gerais, Brazil with special reference to its depositional systems (Tab. 1 and 2), paleoclimatology and synsedimentary crustal extension history.

Within this context a detailed analysis of the Espinhaço Rift, especially of the area Sopa - Guinda near Diamantina (Fig. 1) lead to the identification of the precise magnitude of the source areas of the diamonds contained in the Sopa-Brumadinho Formation and consequently to the location of the primary source rocks of the diamonds.

The primary source rocks of the diamonds (kimberlites or lamproites ?) are deeply altered either by contemporaneous Proterozoic weathering or to less extent by recent weathering. The emplacement of those rocks along normal faults which controlled the local base level establishes a clear relation of cause and effect (consequence). The intrusions are coeval with the fault movements which defined adjacent tectonic cells where coarse clastics are deposited by the relief as well as the erosion products of the host rocks ejected by the explosive volcanism (Fig. 4).

The granulometric constancy of the conglomerates in the different alluvial fans, the uniform grade of diamond within these fans, and the absence of significant fluvial incision demonstrate that the system of synsedimentary normal faults was rift prograding, i.e. in the same direction as the sedimentary flow (Fig. $4)$.

On the other hand, the quartzitic breccia of the Campo Sampaio Member represents a vent breccia which accumulated in maar type craters, sometimes with local sedimentary reworking (Fig. 5).

The individual characteristics of the diamonds of each of the diamond-bearing province within the southern Serra do Espinhaço (Fig. 1) suggest an intrinsic relationship of origin and space of the depository.

Surface peculiarities of the diamonds are contrasting. Stones from the present three hydrographic basins of the region show remarkable traces (unhas, jaças, many chips) of sedimentary reworking whereas lots of diamonds from conglomerates are found virtually intact, indicating negligible transport from the primary source rock to the site of deposition within the Proterozoic coarse clastics.
\end{abstract}

\section{Something hidden, go and find it. Go and look behind the Range. Something lost behind the Range Lost and waiting for you. Go! (Kipling -The Explorer -, Bardet 1973: 177).}

\section{INTRODUÇÃO}

Este trabalho trata do caminho trilhado pelos diamantes até os depósitos metasedimentares da Formação Sopa-Brumadinho (especialmente da Província de Sopa - Guinda), assim como do caminho rastreado, a partir dos depósitos de origem sedimentar, até a descoberta da rocha-matriz desses diamantes.

Foram quase 2 decênios consecutivos de pesquisas e trabalhos de campo e essas rochas, esdrúxulas por origem e descaracterizadas por processos intempéricos proterozóicos e recentes, estiveram, frequentemente, sob as vistas e análises de diferentes pesquisadores da geologia da faixa mediana-central da Serra do Espinhaço.

O advento destas rochas foi possível somente agora não por falta de acuidade dos pesquisadores mas, sobretudo, pela dependência do conhecimento de conceitos modernos e atualizados que permitiram o reconhecimento das mesmas através de meios indiretos, especialmente da análise de bacia.

\section{EVOLUÇÃO DOS CONCEITOS GEOLÓGICOS E DOS CONHECIMENTOS DA GEOLOGIA DA SERRA DO ESPINHAÇO}

Desde o advento da tectônica de placas e da descorberta dos greenstone belts arqueanos ainda nos anos 60 , a ciência geológica tem mostrado notável desenvolvimento conceitual. Significativo, neste sentido, foi, sem dúvida, o desenvolvimento de modelos numéricos para sistemas geológicos e áreas afins e o aperfeiçoamento de técnicas e métodos geofísicos, geocronológicos e litogeoquímicos

Neste particular o fim dos anos 70 e início dos anos 80 marcam a conjugação dos estudos e novos métodos aplicados que, em parte, foram consequência da interação da geologia com ciências e ramos afins, levando à reciclagem e o rápido desenvolvimento e aperfeiçoamento de conceitos em campos diversos, a exemplo do thin skinned tectonics (Boyer \& Elliot 1982), do ciclo dos supercontinentes (Nance et al. 1988), da estratigrafia de sequências (Vail et al. 1977), do simple shear rift (Wernicke 1981), do modelamento de fácies (Walker 1979), dos ciclos relacionados à composição da atmosfera - hidrosfera e sua relação com a climatologia (Grotzinger 1989, Kastings 1989), do reconhecimento de paleosolos precambrianos, 
(Retallack et al. 1984), além do modelamento de processos endógenos diversos (Bird 1979, Anderson 1982, Hynes 1982, England 1983, England \& Mckenzie 1982, Houseman \& E²ngland 1986, Gurnis 1988)

O final dos anos 70 e início dos anos 80 foi, por outro lado, um período marcante no avanço dos conhecimentos da geologia da Serra do Espinhaço, especialmente com a efetivação, em 1979, do Projeto Mapeamento do Espinhaço Meridional, Convênio DNPM / CPRM / UFMG / FUNDEP, a cargo do Centro de Geologia Eschwege.

Com o intuito de dar suporte a esse projeto foi promovido o $1^{\circ}$. Simpósio de Geologia de Minas Gerais, em Diamantina, tendo como temática "A Geologia da Cordilheira do Espinhaço" e, assim, nos anos subseqüentes foram desenvolvidas e apresentadas várias dissertações de mestrado e umas poucas de doutorado abordando diferentes áreas e temas da Serra do Espinhaço Meridional.

Papel importante para o "estado da arte" (daquela ocasião) da geologia dessa faixa orogênica foi desenvolvido pelo Instituto Eschwege com os mapeamentos geológicos de detalhe e semi-detalhe da região central da Serra do Espinhaço Meridional, que culminaram com o refinamento da estratigrafia dessa região (Schöll \& Fogaça 1979). Esse Instituto, também em 1979, foi incorporado à UFMG, que renovou e ampliou significativamente o seu corpo docente, contribuindo assim para a continuidade das pesquisas e multiplicação das áreas investigadas.

Certo é que a estratigrafia proposta por Pflug (1968) mostrava-se, até então (e mesmo até os dias atuais), irreparável, embora fossem muitas as controvérsias e dilemas que cercavam o conhecimento da geologia da região, tais como:

- a idade incerta da deposição dos sedimentos do Supergrupo Espinhaço, sua correlação com o Supergrupo Minas (no sentido de Pflug 1965) e seu período de orogênese;

- origem e significado dos filitos hematíticos (tidos como de origem ígnea desde Correns 1932);

- a estratigrafia das unidades pré-Espinhaço e suas equivalentes regionais;

- a paleogeografia e ambientes sedimentares das unidades do Supergrupo Espinhaço;

- a origem e ambiência das unidades pós-Espinhaço que bordejam a Serra do Espinhaço Meridional (grupos Macaúbas e Bambuí).

Polêmicas e incertezas jaziam, muito mais, acerca $\mathrm{da}(\mathrm{s}) \operatorname{rocha}(\mathrm{s})$ e área(s) fonte(s) dos diamantes que bem valorizaram (e valorizam) os metaconglomerados proterozóicos da Formação Sopa-Brumadinho do Supergrupo Espinhaço e os cascalhos dos aluviões e coluviões quarternários da Serra do Espinhaço e adjacências.

Moraes e Guimarães (1929) e Moraes (1934) propuseram os filitos hematíticos como rocha-matriz dos diamantes da região com base, inclusive, em trabalho experimental sobre $30 \mathrm{~m}$ de tais rochas da
Lavra da Perpétua onde foram encontradas dois pequenos diamantes. A metabrecha quartzítica que intercala-se na unidade superior (Nivel F de Schöll \& Fogaça 1979, Membro Campo Sampaio de Fogaça \& Almeida Abreu 1982) da Formação Sopa-Brumadinho foi interpretada então, por aqueles autores, como "brechas de chaminé" e consideraram essas rochas e as supostas injeções diamantíferas mineralizantes como de caráter ácido.

Barbosa (1951) admitiu que a rocha-matriz dos diamantes eram os filitos hematíticos e cloríticos, contudo opinou que os mesmos mostravam caráter básico.

Pflug (1965), por sua vez, advogou que as postuladas rochas-matrizes dos diamantes da Serra do Espinhaço seriam ultrabásicas tipo kimberlitos, que estariam no ante-país do Geossinclinal Minas, ou seja, no Cráton do São Francisco e recobertas pelas rochas do Grupo Bambuí.

Claro era, na década de 60 , que todas as rochasmatrizes de diamantes conhecidas na superfície do globo mostravam caráter ultrabásico e ultrapotássico e mesmo os kimberlitos do Triângulo Mineiro já haviam sido descobertos. $\mathrm{O}$ estudo das inclusões minerais de diamantes da Serra do Espinhaço efetuadas por Sivisero (1978) veio confirmar a filiação dessas gemas à rochas oriundas do manto astenosférico, situando, portanto, a província diamantífera da região no seu devido ambiente.

Assim, no início dos anos 80, a geografia e paleogeografia dos diamantes da Serra do Espinhaço jaziam na dicotomia da certeza e da dúvida, do fato e do suposto, definindo uma paráfrase do abstrato onde não estabeleciam-se relações de causa e efeito.

O raciocínio linear era imperioso: "sendo a rochamatriz dos diamantes corpos ultramáficos de natureza peculiar, se as mesmas aflorassem na esfera das províncias diamantíferas já teriam sido encontradas"; "os satélites clássicos do diamante - o piropo, a Mgilmenita e o Cr-diopsídio - não acompanham as gemas encontradas na matriz dos metaconglomerados da Formação Sopa-Brumadinho e nos cascalhos dos aluviões quaternários, portanto, os diamantes percorreram grandes distâncias desde a sua fonte deixando para trás os seus satélites"; "os diamantes da Serra do Espinhaço são, em geral, pequenos mas sistematicamente de boa qualidade, evidenciando uma redução de tamanho e seleção através de um grande transporte" (Fig. 1).

Vozes discretas lembravam a possibilidade das rochas kimberlíticas da Serra do Espinhaço terem sido violentamente achatadas, em vista da sua incompetência reológica e por encontrarem-se em zonas de fraqueza e, assim, apresentarem-se atualmente em filetes centimétricos, decimétricos ou métricos. O metamorfismo de baixo grau que se impôs durante a orogênese da Serra do Espinhaço poderia ter modificado (recristalizado) os minerais satélites clássicos do diamante além do que Bardet (1973: 48) 


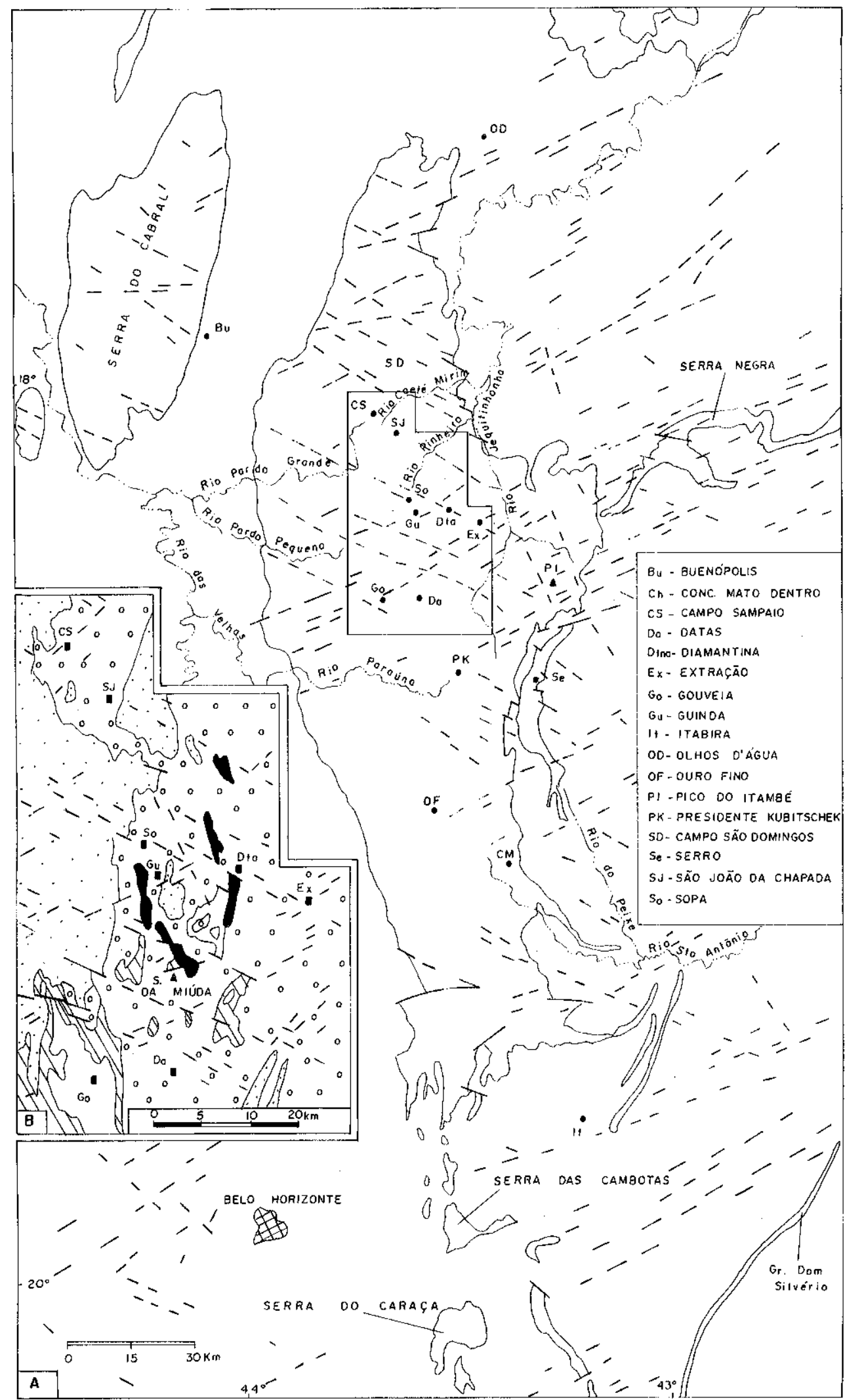

Figura 1: (A): Mapa de Situação da Serra do Espinhaço Meridional localizando as suas principais províncias diamantíferas. Note o trend e expressão dos feixes de lineamentos estruturais. (B): Detalhe da área delimitada na Fig. 1A. Legenda- Branco: Complexo Basal; Hachuriado: Sg. Rio Paraúna; Preto: Fm. Bandeirinha;

Círculos: Fms. São João da Chapada e Sopa-Brumadinho; Pontos: Fm. Galho do Miguel.

Figure 1 A: Location map of the southern Serra do Espinhaço showing its principal diamond-bearing provinces. Note the trend and magnitude of structural lineaments (Fans); B) Detail of inset in Fig. 1 A. - Legend: white:

Basal Complex; hatched: Rio Paraúna Supergroup; black: Bandeirinha Formation; circles: São João da Chapada, Sopa-Brumadinho Formations; stippled: Galho do Miguel Formation. 
descreve os metakimberlitos como rochas diamantíferas precambrianas que não contêm os satélites habituais, ou seja, picro-ilmenita, piropo e o Cr-diopsídio, enquanto os espinélios são muito abundantes.

As rochas diamantíferas (especialmente os kimberlitos), por outro lado, acham-se instaladas quase que invariavelmente em plataformas estáveis, ou seja, em crátons arqueanos. Apenas $0.07 \%$ dos diamantes explorados são oriundos de regiões dobradas (Bardet 1973: 119 - deve ser lembrado, no entanto, que os diamantes dos lamproítos da Austrália ainda não eram conhecidos nessa ocasião).

Todavia, Mitchell (1993) ressalta a presença de kimberlitos estéreis em faixas móveis de rochas precambrianas, adjacentes aos crátons arqueanos. Ainda segundo este autor, lamproítos ocorrem em diferentes ambientes tectônicos, inclusive em faixas móveis incorporadas e cratonizadas nas margens das plataformas, em domínios de crosta e litosfera espessas. Este autor ressalta também que, com exceção da Tanzânia, não encontram-se kimberlitos em riftes e, inclusive esta região da África oriental, considera como uma tentativa sem sucesso das falhas do rifte de penetrar o cráton resistente.

Assim, até o início dos anos 80, todos os registros e conceitos convergiam na direção de que as rochas primárias dos diamantes da Serra do Espinhaço Meridional encontravam-se em regiões distantes do sítio de deposição, considerando-se, inclusive, o conceito então vigente de que todas as unidades do Supergrupo Espinhaço foram depositadas em ambientes marinhos (ver Tab. 1A).

A distribuição geográfica dos metaconglomerados da Formação Sopa-Brumadinho compondo províncias individuais (São João da Chapada, Sopa-Guinda, Datas e Presidente Kubitschek), alinhadas segundo a direção NNW-SSE ressaltava, no contexto dos supostos ambientes marinhos, uma faixa costeira com depósitos deltáicos espaçados ao longo dessa costa. Entretanto, os volumosos depósitos de metaconglomerados de Extração (também diamantíferos) acham-se ao oriente dessa faixa, distante cerca de $22 \mathrm{~km}$ (Fig. 1 A e B) levando a Almeida Abreu e Munhóz (1983) suporem a presença de um domínio insular nesta região e assim indicando que os kimberlitos estariam não somente dentro da bacia mas, sobretudo, nas proximidades ocidentais do distrito de Extração (as paleocorrentes mostram fluxo sedimentar de W para E).

Contudo, duas questões emergiram: 1) os supostos kimberlitos não seriam, necessariamente, relacionados a magmatismo sin-sedimentar; 2) os diamantes poderiam ser provenientes de depósitos sedimentares mais antigos (paleoplacers) retrabalhados durante a sedimentação da Formação Sopa-Brumadinho.

Nos tempos recentes, após Almeida Abreu \& Munhóz (op. cit.), apenas Fleischer (1995) considerou a hipótese de que os kimberlitos responsáveis pela mineralização diamantífera dos metaconglomerados da Formação Sopa-Brumadinho acham-se no seio da bacia, embora encaixados nos sedimentos pré-rifte (Formação São João da Chapada na sua concepção).

A segunda metade dos anos 80 e a primeira metade dos anos 90 foram pródigos no sentido de trazer uma melhor definição dos ambientes sedimentares das formações inferiores do Supergrupo Espinhaço (compare as tabelas 1 A e B), assim como as características paleoclimáticas dos ambientes sedimentares.

Com exceção da Formação Bandeirinha (unidade aposta na base do Supergrupo Espinhaço por Almeida Abreu 1993 e Almeida Abreu \& Pflug 1994), que mostra red beds continentais e, portanto, condições paleoclimáticas semi-áridas ou áridas, todas as demais unidades do Grupo Guinda (seqüência de origem continental relacionada à fase rifte da bacia) depositaram-se em ambientes paleoclimáticos permanentemente úmido sob condições de intenso intemperismo (Almeida Abreu, 1993, 1995). Fundamental para o entendimento do regime paleoclimático vigente durante a deposição das formações São João da Chapada e Sopa-Brumadinho foi a caracterização dos filitos hematíticos - rochas de origem ígnea que cortam ou intercalam-se nestas duas formações - como paleosolos proterozóicos, chegando inclusive a formar paleo-lateritas / -bauxitas (Knauer 1990, Knauer \& Schrank 1993).

Sob o prisma dos ambientes de rifte continental e do regime paleoclimático úmido, uma criteriosa análise de bacia deve dizer de onde vieram os diamantes e qual o sítio de sua rocha-mãe.

\section{ANÁLISE DA BACIA ESPINHAÇO COM ÊNFASE NA PROVÍNCIA DE SOPA - GUINDA}

\section{Generalidades}

Na região de Sopa - Guinda afloram as 4 formações do Grupo Guinda (Tab. 1B), além de xistos do Grupo Costa Sena (Supergrupo Rio Paraúna) que aparecem sob a Formação Bandeirinha a cerca de $2,5 \mathrm{Km}$ a SW de Guinda, estendendo-se dali para sul. A presença dos xistos pré-Espinhaço indica o progressivo soerguimento de blocos em direção ao sul, soerguimento este controlado pelos lineamentos (falhas) de direção NW SE permitindo, assim, que as formações São João da Chapada e Sopa-Brumadinho depositem-se diretamente sobre os xistos (e mesmo sobre o Complexo Basal) a W da Serra da Miúda e na região de Gouveia.

Esses lineamentos foram responsáveis, também, pela rotação anti-horária dos blocos, impondo às camadas da Formação Bandeirinha uma orientação na direção NW - SE a NNW - SSE e a segmentação parcial desta unidade ao longo da sua faixa de afloramentos (Fig. 1B).

O escalonamento dos blocos em degraus sucessivos descendentes para norte é demonstrado, também, pelo espessamento da Formação Bandeirinha nesta direção e, muito mais, pela dominância das fácies eólicas (com 

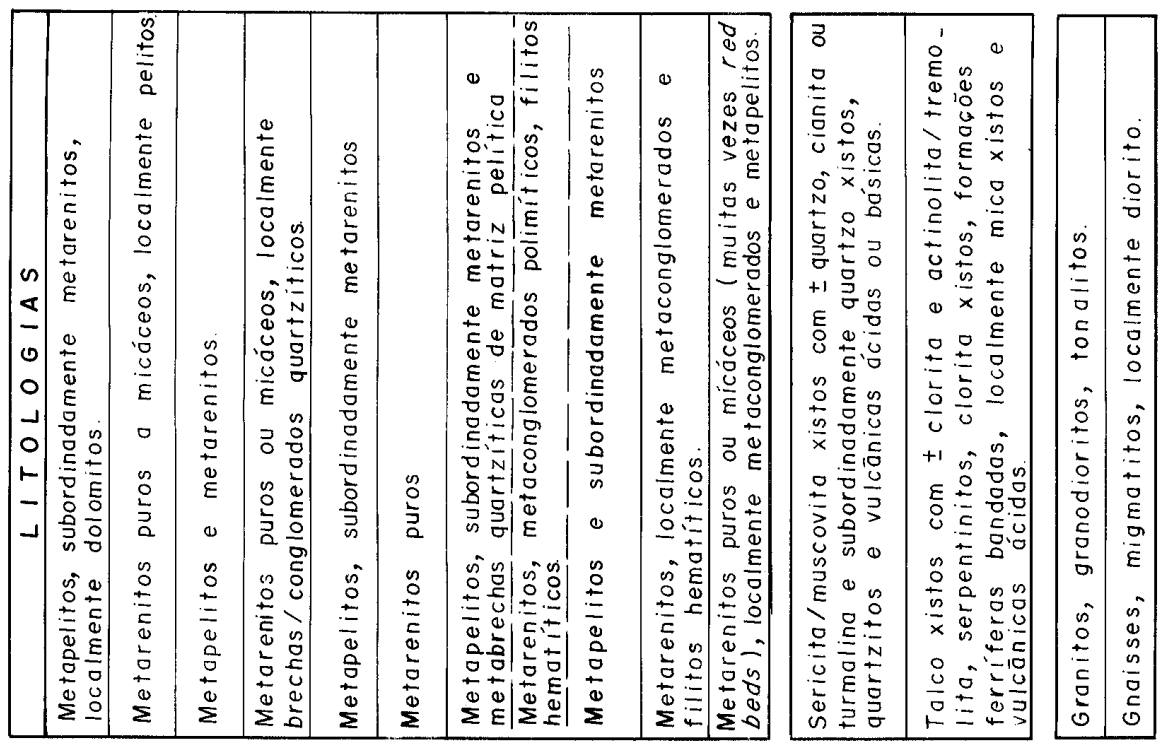

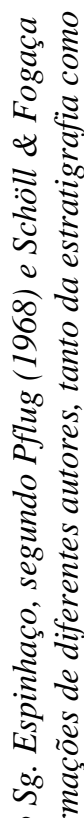

:

造 के

:

弪

ป

๙

$\lambda_{\infty}^{-0}$.

ह

इ 8

ड़

:

ำ.

$\frac{10}{50}$

๘

\begin{tabular}{|c|c|c|c|c|c|c|c|c|c|c|}
\hline & \multicolumn{5}{|c|}{ 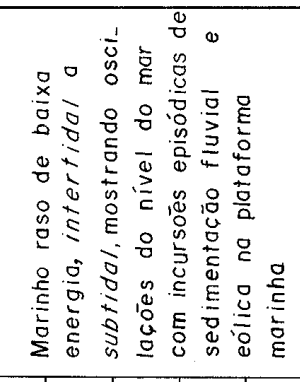 } & 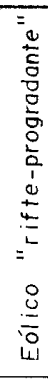 & \multicolumn{2}{|c|}{ 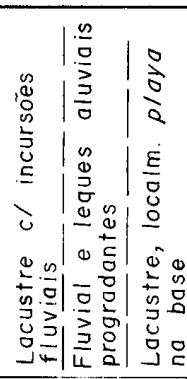 } & 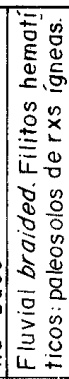 & 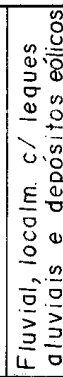 \\
\hline & \multirow{2}{*}{\multicolumn{5}{|c|}{ 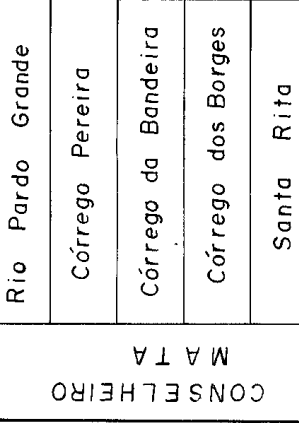 }} & $\begin{array}{l}\bar{\Phi} \\
\stackrel{O}{\Sigma} \\
\bar{\Sigma}\end{array}$ & \multicolumn{2}{|c|}{ 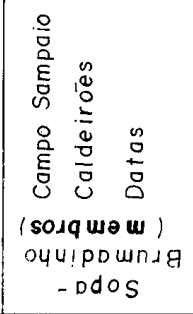 } & 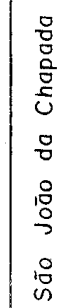 & \\
\hline \multicolumn{2}{|r|}{ - } & & & & & & & & & \\
\hline
\end{tabular}

ป.

芯.

:

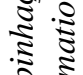

इ.

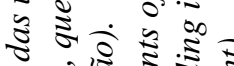

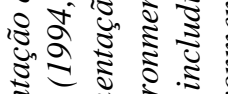

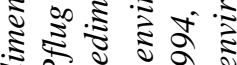

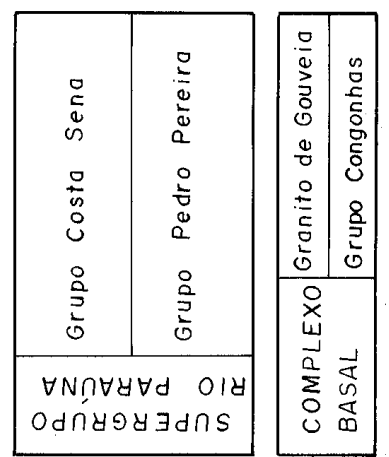

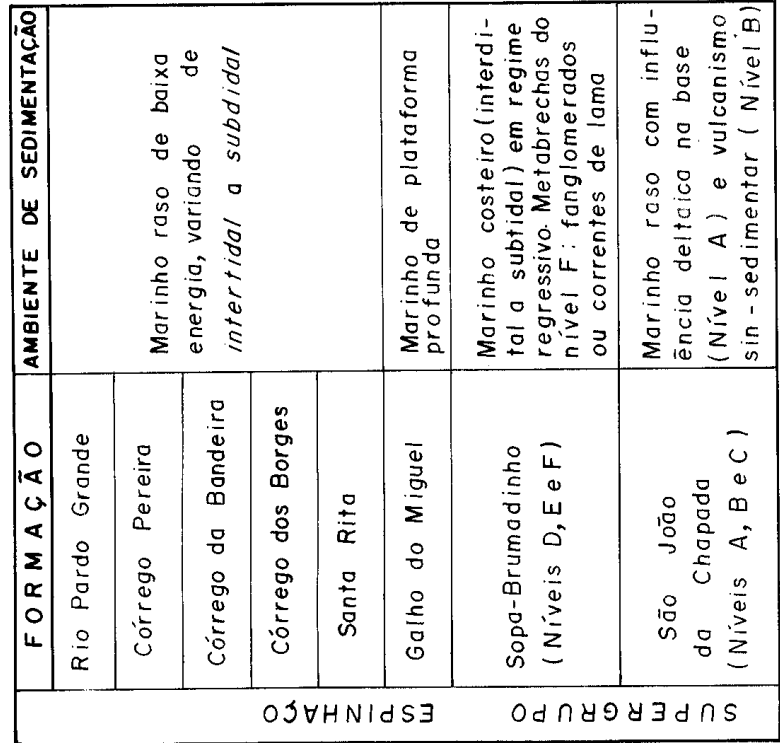

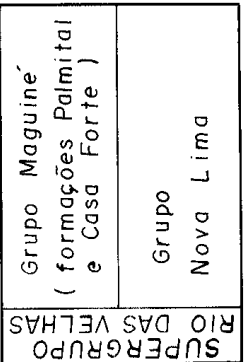

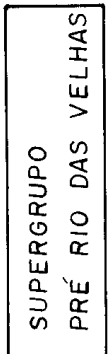

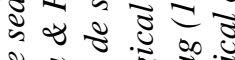

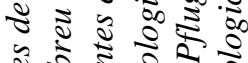

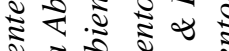

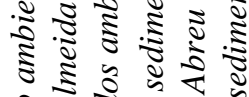

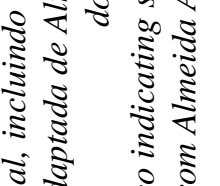

సే

:

造 造

ช్ :

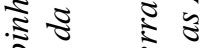

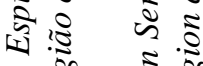

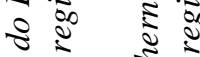

ำ

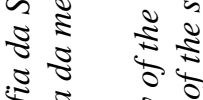

के $\frac{-3}{5}$ है

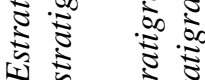

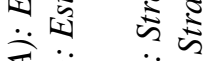

近

造 ๘

हลำ हิ 
red beds) nos afloramentos da unidade a W de Guinda, visto que essas fácies são progradantes sobre as seqüências fluviais que predominam nas seções basais.

Os movimentos verticais dos blocos controlados pela falhas NW - SE a W - E sucederam-se ao longo da fase extensional - mantido o mesmo sentido de escalonamento - considerando que a Formação Galho do Miguel ocupa, progressivamente, domínios mais orientais da superfície da Serra do Espinhaço Meridional em direção ao norte (Fig. 1 B). Deve ser destacado que a extensão do Rifte Espinhaço evoluiu em 3 fases distintas e subsequentes, conforme o registro deixado pelas unidades metassedimentares que marcam essas fases, ou seja, as formações Bandeirinha, São João da Chapada e Sopa-Brumadinho / Galho do Miguel, respectivamente.

\section{A $\mathbf{1}^{\mathrm{a}}$ Fase de Rifteamento}

A formação da calha sedimentar, deposição dos sedimentos, soerguimento, basculamento e profunda erosão da Formação Bandeirinha ocorreram entre 1750 e $1710 \mathrm{Ma}$, considerando os valores de idades dos mais antigos metavulcanitos ácidos do Sistema Espinhaço (1750 Ma - Machado et al. 1989) e as datações dos metavulcanitos intercalados nas formações São João da Chapada e Sopa-Brumadinho (1715 a $1711 \mathrm{Ma}$ Machado et al., 1989).

Portanto, em cerca de 40 milhões de anos a Formação Bandeirinha foi depositada, soerguida e profundamente erodida, mostrando notáveis características de ambientes extensionais com forte controle termal, responsável pelo arqueamento das falhas normais lístricas e exemplo de Basin and Range do SW dos Estados Unidos (Spencer 1984, Yin 1991).

O contato da Formação Bandeirinha com os xistos do Grupo Costa Sena define um plano de descontinuidade que intercepta tanto as camadas desta formação, como a foliação dos xistos subjacentes caracterizando, portanto, um detachment fault (Almeida Abreu 1993). Esta descontinuidade é ressaltada também pelo expressivo contraste deformacional e metamórfico entre os metarenitos e xistos das unidades em questão, feição característica de detachment que assentam-se sobre core-complex (Buck 1988).

A pertinaz deformação destes xistos, com feições blastomiloníticas generalizadas (Schöll \& Fogaça 1979), geradas em ambiente de crosta-média (Hoffmann 1983), aliado às relações de contato com o embasamento cristalino subjacente que, a exemplo do contato superior ressalta-se como uma detachment fault, sugere que suas feições dominantemente milonítica foram geradas pela evolução da tectônica extensional imposta à Formação Bandeirinha, embora os protólitos (sedimentos e vulcanitos) do Grupo Costa Sena possam ser de idades bem mais antigas em relação ao Sistema Espinhaço. Reforça esta assertiva o fato destes xistos mostrarem espessuras aparentes de até 600 metros e, mesmo assim, a deformação milonítica domina todo o conjunto contrariando, portanto, o princípio da thin skinned tectonics e lembrando ainda que processos de milonitização envolvendo conjuntos tão espessos são reportados em ambientes de extensão crustal (Davis 1983).

\section{A $2^{\text {a }}$ Fase de Rifteamento}

Após um longo período de erosão, o relevo residual da Formação Bandeirinha é denunciado pelos depósitos de fanglomerados (metabrechas) que caracterizam a base da Formação São João da Chapada quando assentada diretamente sobre aquela unidade. Estes depósitos marcam o início de uma generalizada subsidência da maior parte da superfície ocupada atualmente pela Serra do Espinhaço Meridional, onde instalou-se uma larga e extensa bacia fluvial. O início da subsidência foi acompanhada por vulcanismo básico fissural com derrames e deposição de tufos pouco espessos sobre superfícies relativamente vastas que, sob o clima vigente, suas camadas superiores foram fortemente alteradas e transformadas em lateritas e/ou bauxitas (Knauer 1990) sendo representadas atualmente pelos filitos hematíticos.

As fácies sedimentares da Formação São João da Chapada são virtualmente constantes, caracterizando sistemas fluviais braided com fluxo sedimentar predominante de $\mathrm{W}$ para $\mathrm{E}$ em ciclos fining upward. Essas características faciológicas e sua constância no universo da bacia caracteriza, por sua vez, um período de calmaria tectônica.

\section{A $3^{\text {a }}$ Fase de Rifteamento}

Um novo pulso termal foi responsável por intensa atividade crustal com a instalação de calhas lacustres em grabens justapostos às adjacências orientais de horsts, dispostos ao longo da faixa mediana-central da Serra do Espinhaço Meridional. Os lineamentos NW SE (Fig. 1A e B) mais uma vez foram muitos ativos, comportando-se como falhas de transferência, segmentando parcialmente a bacia lacustre e individualizando as províncias diamantíferas que coincidem com os grandes sistemas de leques aluviais que progradaram as calhas lacustres, ou seja, Campo São Domingos, Campo Sampaio - São João da Chapada, Sopa - Guinda, Datas, Presidente Kubitschek, Parauninha (a SSE de Ouro Fino) e Serra dos Cambotas (Fig. 1A e B).

As falhas de transferência movimentaram-se tanto longitudinalmente (rejeito direcional) como verticalmente, promovendo o basculamento de blocos. Isto mostra-se explícito a W e SW de Guinda, assim como ao N e NW da Serra da Miúda, onde camadas das formações Bandeirinha e Sopa-Brumadinho exibem atitudes W - E a NW - SE justamente ao lado destes lineamentos e a clivagem $\mathrm{N}$ - S (estrutura gerada durante a fase orogenética) corta sub-ortogonalmente estas camadas demonstrando, portanto, que a forte rotação e basculamento ocorreu durante a fase de sedimentação da Formação Sopa-Brumadinho. Os movimentos verticais de blocos foram mais expressivos a $\mathrm{N}, \mathrm{NE}$ e 
E da Serra da Miúda, visto que a Formação São João da Chapada foi completamente erodida permitindo, assim, a deposição da Formação Sopa-Brumadinho diretamente sobre a Formação Bandeirinha e levando à deposição de extensos fanglomerados que caracteriza a porção basal daquela formação nessa região.

Entre as províncias diamantíferas (representadas pelos grandes depósitos de ruditos) aparecem, localmente, pacotes de metaconglomerados da Formação Sopa-Brumadinho que podem ser também diamantíferos, embora predominem, nesses domínios, metarenitos ricos em laminações plano-paralelas milimétricas a sub-centimétricas evidenciando a progradação - assoreamento das calhas flúvio-lacustres através de fluxos em lençol (sheet floods).

Considerando os registros descritos até aqui, aliados às informações que serão adicionadas conjuntamente a seguir, várias relações de causa e efeito são dimensionadas acerca da história sedimentar e comportamento crustal durante a deposição da Formação Sopa-Brumadinho:

1) As províncias de ruditos estão assentadas em segmentos mais móveis do rifte, onde a intensa movimentação crustal controlada por falhas normais, promoveu a profunda erosão dos blocos elevados e a formação de leques aluviais progradantes nas bordas dos grabens adjacentes. É razoável supor que a maior mobilidade desses domínios foi conseqüência do vulcanismo (representado atualmente por xistos verdes e filitos hematíticos), ou seja, a conseqüência da atividade de plumas mantélico-astenosféricas de $3^{\text {a }}$ Ordem - no sentido de Maruyama (1994) -, alimentadas (considerando a expressão ultra-regional do fenômeno) por pluma de $2^{\mathrm{a}}$ ordem alojada sob a crosta, seja no sentido de Lemoine et al. (1987), seja no sentido de Bird (1979), conforme as Figura 2 e 3, respectivamente.

2) A expressiva quantidade de óxidos de ferro (especialmente hematita) na Formação SopaBrumadinho, seja na matriz dos metaconglomerados, seja como laminações ou concreções ferruginosas nos metarenitos, vem indicar que o aporte do ferro (como exalações primárias ou pelo enriquecimento através de processos intempéricos) foi decorrência do vulcanismo sin-sedimentar. Considerar o enriquecimento de ferro como a conseqüência do retrabalhamento sedimentar de formações ferríferas não parece razoável, em vista da quase absoluta ausência de seixos desses supostos depósitos nos metaconglomerados da Formação SopaBrumadinho. Por outro lado, a absoluta ausência de red beds nesta formação, a despeito da expresssiva quantidade de ferro nos depósitos subaéreos, vem reforçar um ambiente climático excessivamente úmido durante a sua deposição.

3) A província diamantífera de Extração não alinhase com as demais províncias diamantíferas que achamse ao longo da faixa mediana-central da Serra do Espinhaço Meridional (Fig. 1A e B). A petrografia e as texturas dos ruditos de Extração têm, também, características peculiares, tais como a matriz predominantemente pelítica, a presença freqüente de blocos de diâmetro superior a $50 \mathrm{~cm}$ (as vezes com mais de 1 metro), a presença comum de grãos de feldspatos (microclina e plagioclásios) que também aparecem nos metarenitos da região. Como as províncias de Sopa - Guinda e de Extração estão justapostas (Fig. 1B), e considerando que as paleocorrentes de ambas mostram fluxo sedimentar predominante de $\mathrm{W}$ para $\mathrm{E}$, significa dizer que as mesmas não foram calhas sedimentares contemporâneas, visto que a área fonte (tectonicamente muito ativa) da Província de Extração teria fornecido também volumes consideráveis de ruditos para a borda oriental da Província de Sopa - Guinda (com fluxo de E para W) e não há qualquer indício de tais depósitos. Portanto, ao que parece, a deformação extensional migrou progressivamente para E (cf. Almeida Abreu 1993, 1995), segundo 2 fatores que trabalharam na mesma direção: a) como a calha sedimentar é assimétrica (meio-graben) recebe um significativo aporte de sedimentos na borda mais ativa tectonicamente, levando à rotação progressiva da calha pelo peso diferenciado e pela ação contínua de falhas normais lístricas que no

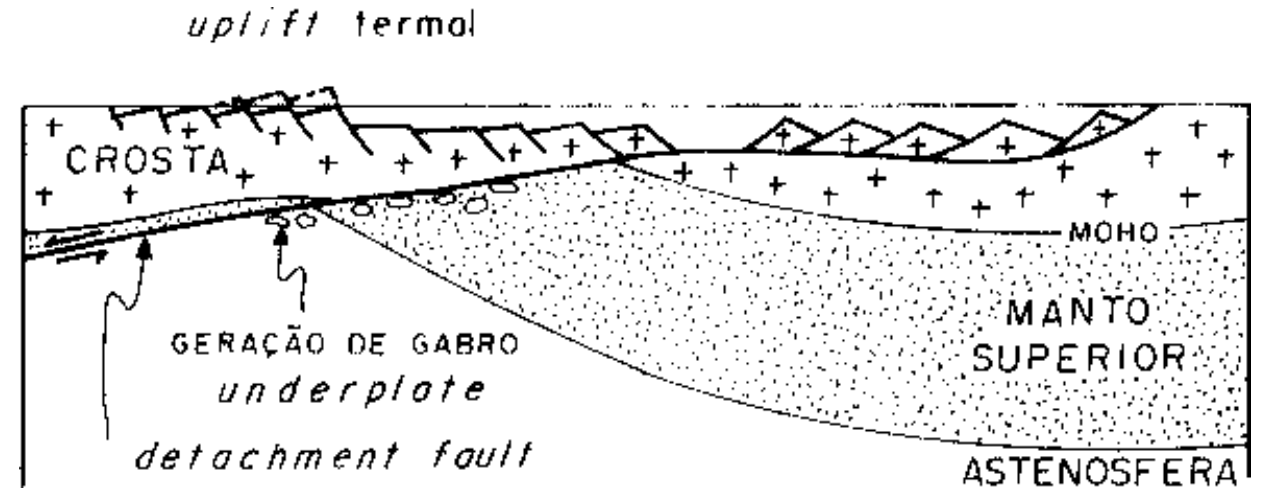

Figura 2: Modelo de rifteamento com delaminação litosférica associada, segundo Lemoine et al. (1987). Figure 2: Model of rifting with lithospheric delamination (after Lemoine et al. 1987) 
curso da sedimentação perdem sua capacidade de movimento devido ao aumento significativo do atrito; b) a crosta em extensão foge progressivamente do foco de calor subcrustal que, por sua vez, irá intumescer outro segmento da superfície e o sítio ideal será, sem dúvida, na zona oposta da borda tectonicamente ativa da $1^{\text {a }}$ calha sedimentar, visto que a rotação do meiograben promove a reativação (ou formação) de falhas neste domínio, propiciando a fuga de calor e a acomodação da distensão nestas falhas de alto ângulo recém-ativas.

4) A atividade de plumas mantélicas associadas aos processos de rifteamento e fragmentação continental estão largamente documentados na literatura. Embora no magmatismo kimberlítico este processo não seja universal, está bem documentado em Yakoutie (Sibéria), onde os kimberlitos migraram de $\mathrm{S}$ para $\mathrm{N}$ 0,4 a 0,5 cm/ano (Bardet 1973), na borda ocidental do Plateau do Colorado e no Arizona (USA) em 2 episódios distintos com velocidades de $3 \mathrm{~cm} /$ ano (Bird 1979), bem como no Craton do Kaapvaal onde um trend linear definido pelos Kimberlitos do Grupo 2 mostram idades decrescentes de NE para SW sugerindo atividade de pluma (Mitchell 1993). Admitir atividade de pluma a partir da Província de Sopa - Guinda com migração para ESE passando pela província de Extração até as cabeceiras do Ribeirão Soberbo, (ao N do Pico do Itambé, Fig. 1A), situa-se dentro do razoável considerando os registros sedimentares e de atividade crustal descritos, ainda mais que existem várias outras evidências irrefutáveis de que os diamantes encontrados nos metaconglomerados e metabrechas da Formação Sopa-Brumadinho são oriundos de fontes primárias muito próximas, conforme discutido adiante.

Os metaconglomerados da Província de Sopa Guinda afloram, geralmente, em pacotes com espessuras de quase 1 até 3 a 4 metros (raramente com espessuras que podem alcançar 8 metros) e com extensões laterais de alguns metros a pouco mais de
100 metros. É notável que os pacotes de menor espessura acomodam-se, em geral, em canais de altas razões largura/altura (p. ex., adjacências ocidentais da Lavra do Chalé, adjacências W e NW da Serra da Galinha e Lavra do Bambá), ou como extensos depósitos tabulares do tipo sheet floods.

Os depósitos mais espessos e extensos (p. ex., lavras Diamante Vermelho, Lavrinha e Brumadinho) compõem depósitos do tipo debris flows (Foto 1) coalescentes, clasto-suportados, com contatos inferiores tabulares ou, localmente, erosivos. Os debris flows compõem leques grosseiros de espessuras métricas a decamétricas progradantes em calhas lacustres adjacentes definindo, portanto, fandeltas ou edificando leques aluviais s. s.

Importante e interessante é que os depósitos de metaconglomerados estão encerrados em celas individuais, definidas como unidades de sedimentação através de falhas sin-sedimentares que controlaram o nível de base local. É possível que algumas dessas celas tenham sido unidades de sedimentação contemporâneas mas, exclusivamente, justapostas ao longo da direção aproximadamente $\mathrm{N}$ - S e, jamais, contíguas - como unidades de sedimentação contemporânea -, segundo o eixo W - E. Isto pode ser deduzido em função de:

1) as falhas sin-sedimentares têm orientação geral $\mathrm{N}$ - S a NNW - SSE e mostram extensões variáveis na escala de algumas dezenas de metros a poucas centenas de metros. Uma mesma falha desaparece e reaparece espaçadamente segundo o referido trend, rigorosamente alinhada ou ligeiramente deslocada (embora com os segmentos sub-paralelos entre si). Nalguns locais essas falhas exibem estruturas do tipo rollover folds associadas. Esse comportamento é típico das falhas normais de riftes, seja na escala regional (Scott \& Rosendahl 1989, Nelson 1992), seja na escala do halfgraben (Leeder et al. 1988).

2) cada cela acha-se "lacrada" por sedimentos fluviais de canais entrelaçados de porte centimétrico a

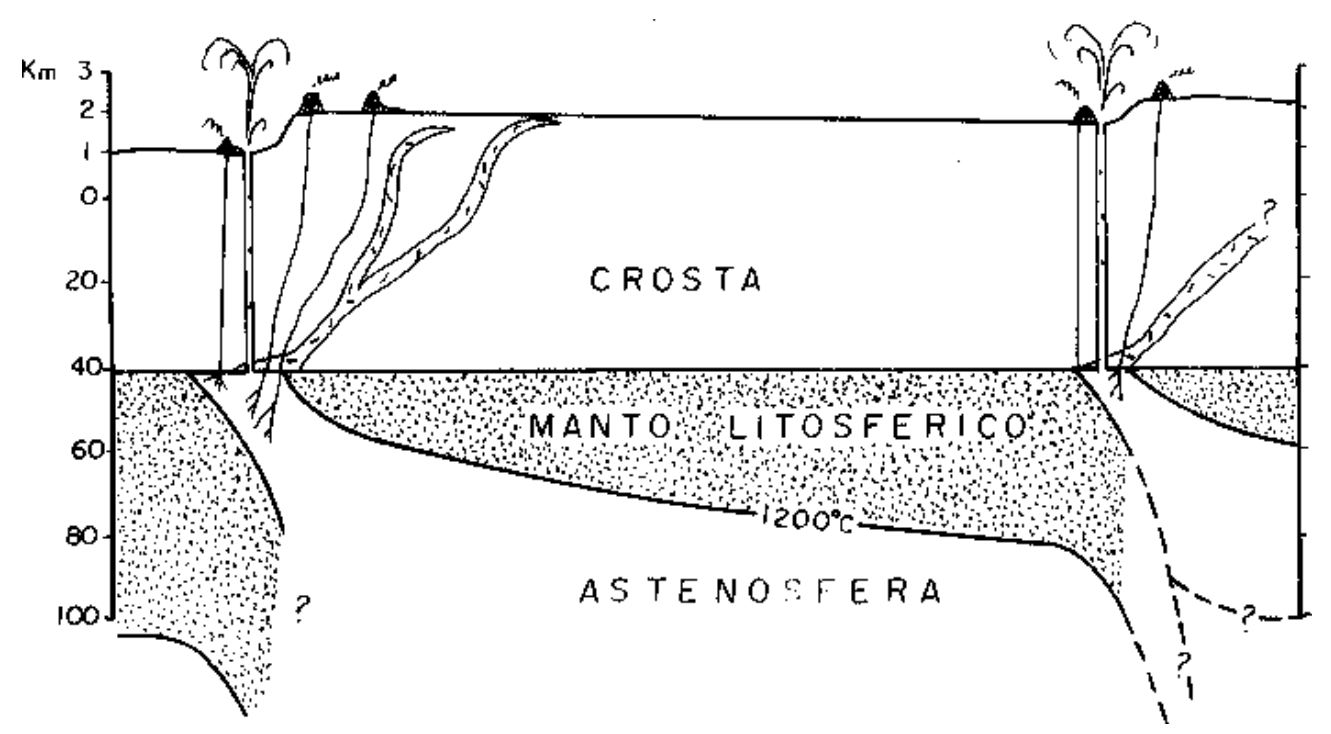

Figura 3: Delaminação litosférica com vulcanismo basáltico e kimberlítico associado, segundo Bird (1979).

Figure 3: Lithospheric delamination with associated basaltic and kimberlitic volcanism (after Bird 1979). 
decimétrico com sheet floods intercalados, evidenciado ciclos finning upward. A contemporaneidade de celas justapostas segundo a direção W - E, considerando que o fluxo sedimentar foi claramente de $\mathrm{W}$ para $\mathrm{E}$, levaria, inevitavelmente, à incisão de canais cortando os depósitos da cela ocidental adjacente e isto não é observado em nenhum local.

Por outro lado, os depósitos de metaconglomerados das celas mais orientais da Província de Sopa - Guinda (p. ex., lavras Lavrinha e Brumadinho) contêm clastos tão grandes como os das celas mais ocidentais (p. ex., lavras dos Caldeirões e do Bambá). Isto demonstra claramente que se a área fonte dos detritos tivesse recuado progressivamente ou mantido-se mais ou menos fixa, a granulometria diminuiria progressivamente na direção do fluxo ou, senão, incisões e retrabalhamento generalizado das celas ocidentais ocorreriam à medida que as adjacentes orientais fossem sendo preenchidas. Deve ficar claro, no entanto, que uma mesma cela pode ter recebido um ou mais leques em pulsos episódicos (haja visto a expressiva quantidade de diamantes retirada dos flúvios que drenam - direta ou indiretamente - essa província) e em parte retrabalhando os blocos adjacentes soerguidos que, em última análise, contêm os depósitos das celas imediatamente a W (Fig. 4), considerando a presença de seixos e matacões de rochas rudáceas nos depósitos de metaconglomerados, assim como a presença de falhas sin-sedimentares basculando e soerguendo pacotes de metaconglomerados (Foto 2).

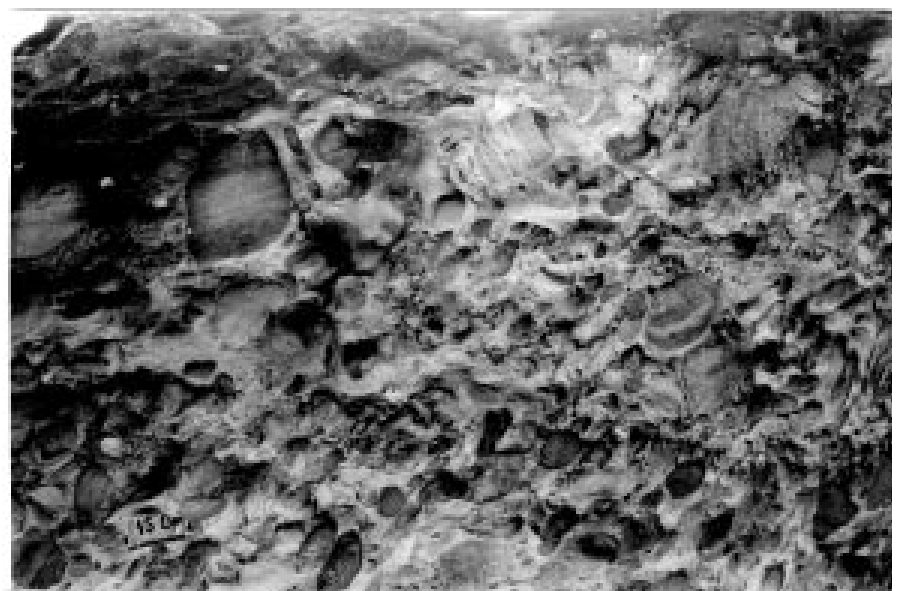

Foto 1: Metaconglomerado polimítico clasto-suportado da Fm. Sopa-Brumadinho (Lavra da Sopa). Note a imaturidade textural e o variável grau de arredondamento dos clastos.

Photo 1: Polymictic clast supported conglomerate of the Sopa-

Brumadinho Formation (Sopa Mine). Note the textural immaturity and the varying degree of rounding of the clasts.

A expressão das falhas sin-sedimentares (em termos de rejeito) parece variável, mas os corpos maiores de metaconglomerados (p. ex., domínio das lavras Diamante Vermelho - Lavrinha e lavras do Bambá Colônia) foram depositadas ao lado de falhas com rejeitos verticais de pelo menos poucas centenas de metros, considerando o posicionamento topográfico das elevações imediatamente ocidentais que são edificadas em metarenitos da Formação São João da Chapada. É notável, também, que estas elevações moldam anticlinais de eixos aproximadamente $\mathrm{N}-\mathrm{S}$, com flancos orientais exibindo mergulhos fortes (35 - 50) e flancos ocidentais com mergulhos bem suaves (10 20), ou seja, contrário ao padrão $\mathrm{W}$-vergente dos dobramentos gerados durante a fase orogenética e ressaltando, portanto, que essas estruturas de geometria peculiar foram moldadas pela tectônica extensional sinsedimentar.

Em algumas falhas de transferência de direção WNW - ESE que compartimentam em segmentos adjacentes as celas de depósitos rudíticos e porções da calha lacustre estão registrados significativos movimentos verticais, especialmente a falha que passa no povoado de Guinda pois, a WNW desta vila a elevação de metarenitos da Formação Bandeirinha (divisor de águas para as vertentes dos córregos das Pedras, Colônia e Caldeirões) é recoberta por metarenitos e filitos hematíticos da Formação SopaBrumadinho, ou seja, a Formação São João da Chapada foi completamente erodida antes e/ou durante a deposição daquela formação.

Considerando a progradação dos sedimentos de W para E e como não observa-se variação na granulometria dos depósitos de ruditos e tampouco

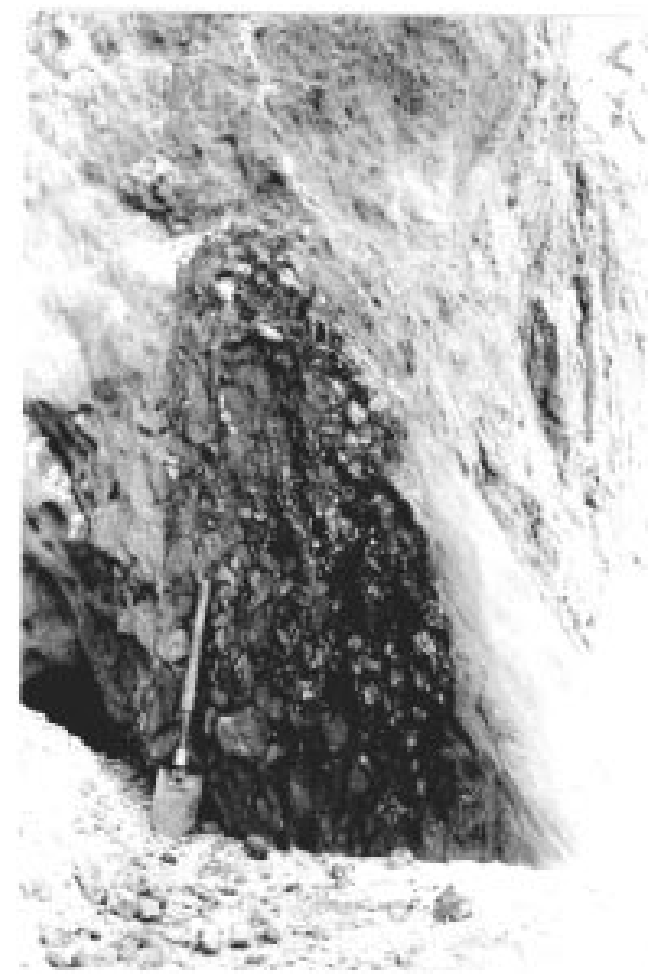

Foto 2: Basculamento de meta-arenitos econglomerados da Fm. Sopa-Brumadinho

(Lavra dos Caldeirões) provocado por falha sin-sedimentar.

Photo 2: Tilting of arenites and conglomerate of the Sopa-Brumadinho Formation caused by synsedimentary faulting (Caldeirões Mine). 
incisões fluviais significativas nessa direção, torna-se imperioso admitir que a sedimentação progrediu através da ativação das falhas sin-sedimentares de direção N $\mathrm{S}$ com escalonamento progressivo no sentido do fluxo sedimentar, ou seja, caracterizando falhas sinsedimentares pro-rifte, contrariando a proposta de Almeida Abreu $(1993,1995)$ de que a sedimentação teria sido controlada por limited back-faulting no sentido de Heward (1978). dos Caldeirões não são mais ricos em diamantes do que os depósitos das lavras Lavrinha e Brumadinho.

Pelo exposto, não é ousadia supor que:

1) As falhas sin-sedimentares da Província de Sopa - Guinda criaram as variações topográficas para estabelecer o receptáculo e o gradiente necessários no sentido de transportar e sedimentar os diversos depósitos de ruditos da região (Fig. 4).

2) Essas falhas estão ocupadas, quase que

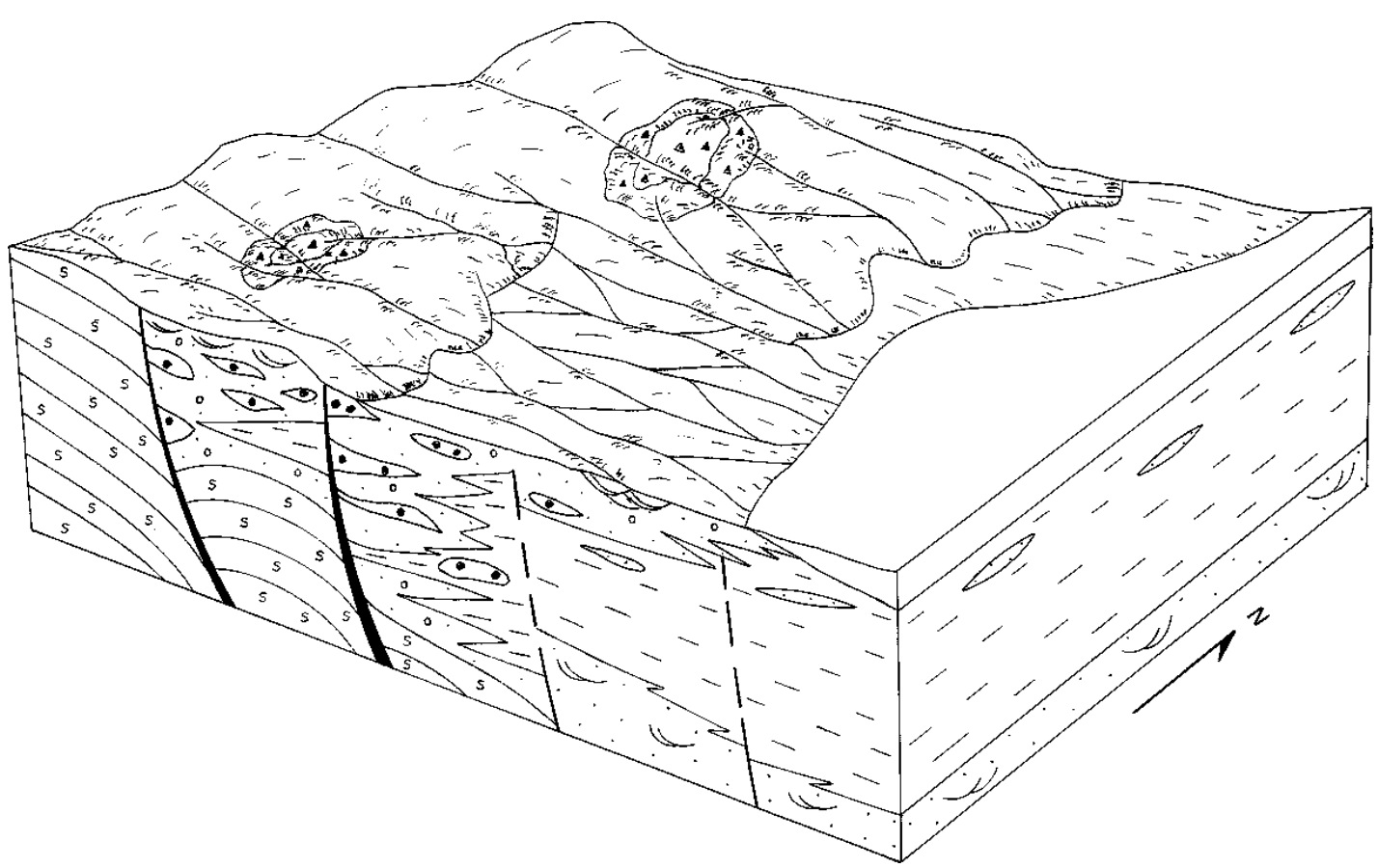

Figura 4: Bloco-diagrama esquemático mostrando a progradação da sedimentação da Formação SopaBrumadinho, controlada pela atividade tectônica das falhas sin-sedimentares pro-rifte com vulcanismo explosivo associado. Legenda - (s): Fm. São João da Chapada; pontos: metarenitos; traços: metapelitos lacustres; círculos cheios: leques aluviais; circulos vazios: corpos menores de metaconglomerados.

Figure 4: Schematic block diagram showing progadation of the sedimentation of the Sopa-Brumadinho Formation controlled by tectonic activity of synsedimentary faults pro-rift associated with explosive volcanism. Legend: s: São João da Chapada Formation; stippled: arenites; traces: lacustrine pelites; dots: alluvial fans; circles: smaller lenses of conglomerates.

Tendo-se em mente que a distância linear entre os depósitos de ruditos da Província de Sopa - Guinda no sentido do fluxo sedimentar soma aproximadamente 7 $\mathrm{km}$ e que a granulometria e o volume dos mesmos não sofrem variações significativas, uma questão emerge, inevitavelmente: como e por que foram gerados tantos fragmentos grosseiros de rochas para alimentarem os depósitos de metaconglomerados?

No sentido da obtenção de uma resposta consistente devem ser adicionadas mais 2 informações importantes: a primeira é que, a despeito do volume e granulometria dos depósitos em questão, não há qualquer evidência de retrabalhamento direto do embasamento cristalino, seja pela presença de seixos, seja pela presença de minerais típicos como feldspatos e a segunda é que mesmo na direção do fluxo sedimentar os teores médios de diamantes nos depósitos de metaconglomerados são aproximadamente iguais, ou seja, os depósitos da Lavra invariavelmente, por rochas ígneas intrusivas que mostram espessuras métricas a decamétricas (Fotos 3 e 4) e extensão de dezenas de metros a poucas centenas de metros. O vulcanismo foi do tipo explosivo e, portanto, causou a erosão das encaixantes levando ao despejo de somas consideráveis de fragmentos de rochas na superfície (Fig. 4).

3) Esse vulcanismo foi responsável pela mineralização de diamantes nos cascalhos que deram origem aos depósitos de metaconglomerados da região e não é de se estranhar, portanto, que os mesmos não sejam mineralizados também em minerais de metais nobres.

Os registros geológicos subsequentes são ainda mais contundentes no sentido de caracterizar que as rochasmãe dos diamantes da Serra do Espinhaço estão, não apenas no seio da bacia mas, sobretudo, nas proximidades dos depósitos metasedimentares mineralizados nessa gema, conforme será exposto a seguir. 


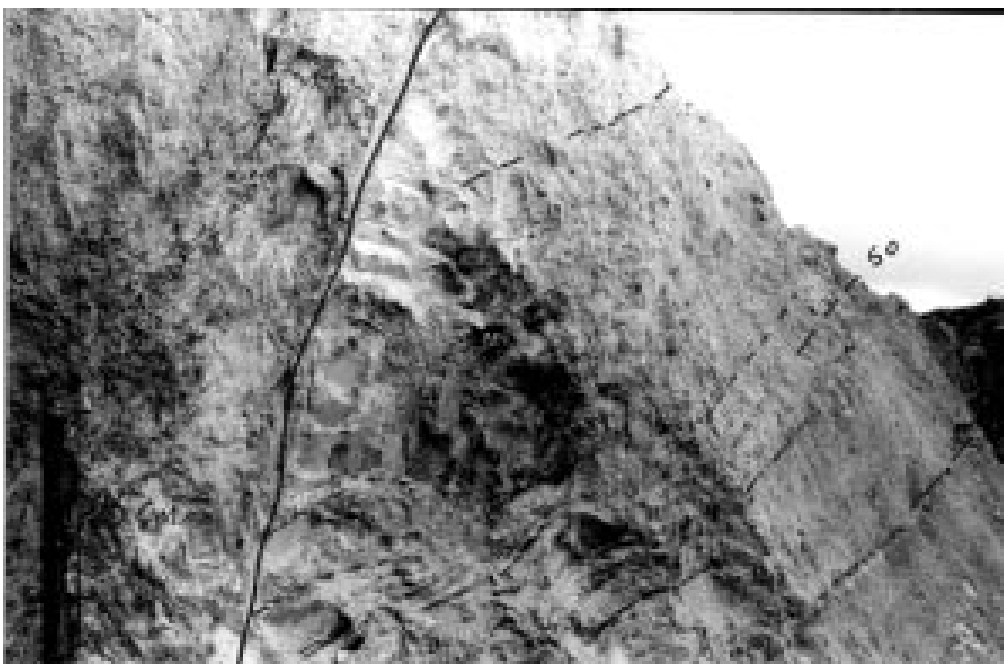

Foto 3: Dique de rocha ígnea alojado em falha sin-sedimentar (Formação Sopa-Brumadinho, Lavra dos Caldeirões).

Photo 3: Dike of igneous rock emplaced along synsedimentary fault (Sopa-Brumadinho Formation, Caldeirões Mine).

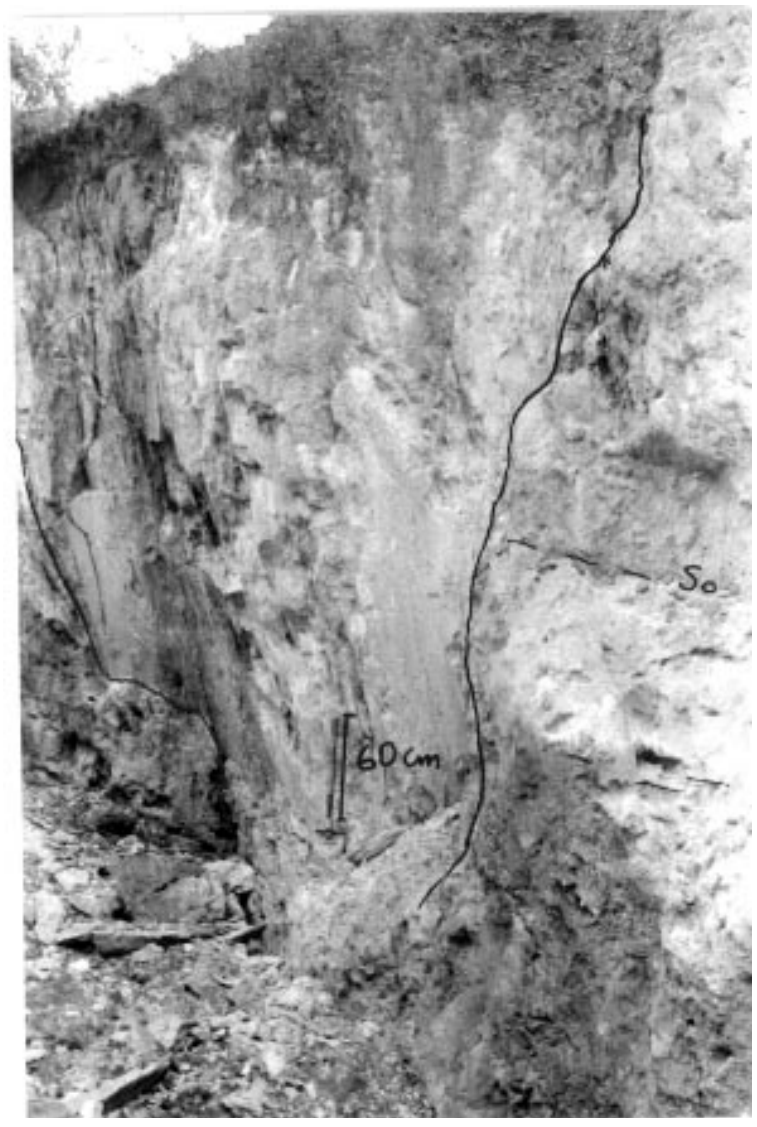

Foto 4: Dique de rocha ígnea encaixado em meta arenitos/ -conglomerados da Formação Sopa Brumadinho (Lavra do Chalé.

Phto 4: Dike of igneous rock emplaced in arenites and conglomerates of the Sopa-Brumadinho Formation (Chalé Mine).

O arrefecimento da tectônica extensional do Rifte Espinhaço na faixa entre Sopa - Guinda e Campo São Domingos (Fig. 1A e B) é marcado pela sedimentação de pelitos sobre diversos locais dessa faixa que caracterizam o Membro Campo Sampaio (v. Tab. 1B). Eventualmente aparecem associados aos metapelitos deste membro pacotes de metabrecha quartzítica de matriz pelítica, exibindo formas e espessuras variadas.

Essa metabrecha aparece, localmente, em níveis decimétricos predominando, no entanto, pacotes de espessuras métricas (as vezes superando 4 metros) e extensões muitas vezes superiores a 100 metros. Pode aparecer preenchendo canais de baixas razões largura/ altura, como camadas irregulares ou como pacotes que, em corte, acunham-se rapidamente em ambas direções e sua superfície superior trunca sedimentos pelíticos e arenosos finamente estratificados demonstrando, portanto, a geometria típica de depósitos do tipo fanglomerado (Fig. 5).

A metabrecha é muito grosseira, exibindo fragmentos completamente angulosos a subangulosos (Foto 5) de dimensões milimétricas a decimétricas (frequentemente com diâmetros superiores a $30 \mathrm{~cm}$, raramente com mais de $50 \mathrm{~cm}$ ) e têm como característica peculiar a coloração "primária" rosaavermelhada (a predominância de fragmentos dessa cor sem variações de tonalidades concêntricas e dispostos ao lado de outros fragmentos completamente brancos, proíbe considerar a cor avermelhada da contaminação recente por soluções ricas em óxidos de ferro).

O retrabalhamento sofrido por transporte pelos fragmentos dessa metabrecha é virtualmente inexistente sendo mud flows (fluxo de detritos coesivos), sem dúvida, o único meio de transporte capaz de levá-los até o sítio de deposição mantendo essas características. Com base nas feições de depósitos flanglomeráticos apresentada, nalguns lugares, por essa metabrecha (Foto $6)$, deve-se esperar que, nesse período de calmaria tectônica no âmbito do rifte, reativações tectônicas locais de falhas ocorressem e isto está ressaltado nos depósitos fluviais de canais entrelaçados que preenchem um largo canal que promoveu a incisão de mais de 2 dezenas de metros nos depósitos lacustres do Membro Campo Sampaio, aflorante na ribanceira oriental do Ribeirão do Guinda a cerca de 500 metros ao sul de sua confluência com o Ribeirão das Pedras.

O fenômeno que determinou a geração dessa metabrecha foi de abrangência regional, pois a mesma aflora, de certa forma extensivamente, a NNE de 


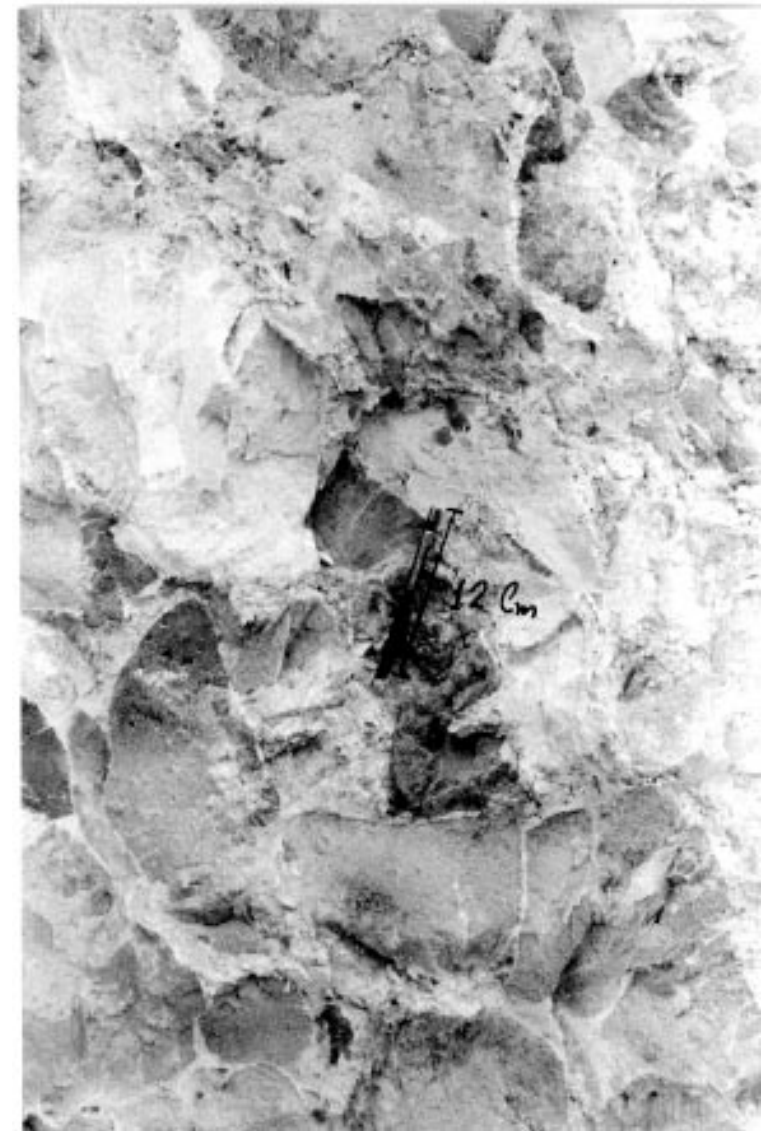

Foto 5: Metabrecha quartzítica (Membro Campo

Sampaio, Lavra Brumadinho). Note que os

fragmentos são completamente angulosos $e$ a matriz é pelítica.

Photo 5: Quartzitic breccia of angular clasts within a pelitic matrix. (Campo Sampaio Member, Brumadinho Mine).

Guinda, a N de Sopa, e nas regiões de Morrinhos, Begônia, São João da Chapada, Campo Sampaio e Jobô e, localmente, no ocidente do Campo da Dona, a sul de Guinda, em Extração (Lavra do Cavalo Morto), Serra do Pasmar, a sul de Barão de Guaicuí, a NNE de Chapadinha, a NNW de Cuiabá (estes 2 últimos lugares no município de Gouveia, a NNW da sua sede) e a N de Datas. Deve ser ressaltado que essa metabrecha aparece exclusivamente nas sequências do Membro Campo Sampaio, a não ser uns poucos depósitos recobrindo e/ou ocupando incisões em camadas do Membro Caldeirões da mesma formação.

Essa metabrecha é mineralizada em diamantes, especialmente nos depósitos de Jobô, Campo Sampaio e São João da Chapada e, de modo menos significativo, nos depósitos de Begônia, Morrinhos, Brumadinho, Barro Branco e Campo da Dona.

O exotismo da metabrecha em questão foi também ressaltado por Bardet (1977: 95) que menciona inclusive os possíveis restos de intrusões ígneas associadas, observados por diferentes autores.

Mais uma característica particular da metabrecha quartzítica do Membro Campo Sampaio é a constância e monotonia dos seus fragmentos, contendo quase que

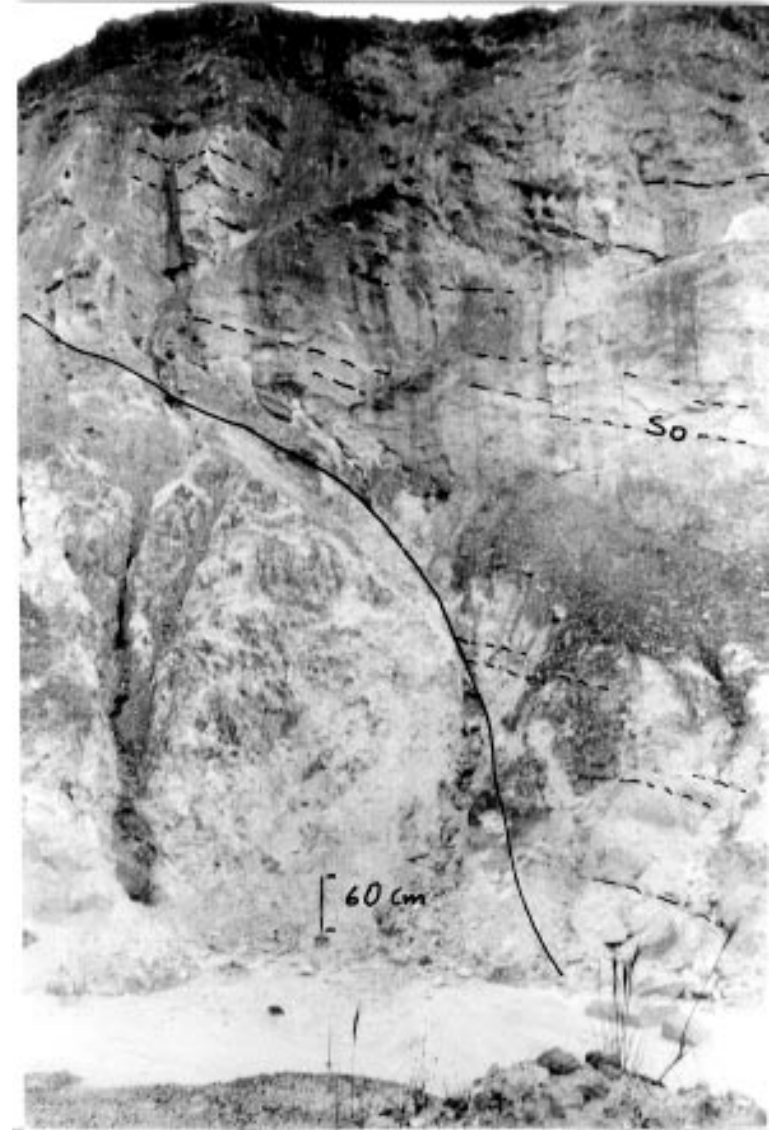

Foto 6: Mesmo afloramento da foto anterior. $O$ corpo de metabrecha (parte esquerda inferior da foto) mostra feição de depósito tipo fanglomerado. Photo 6: Same outcrop as foto 5. The breccia (lower left) shows characteristics of a fanglomerate type deposit.

apenas clastos de metarenitos a não ser raríssimos seixos subarredondados a arredondados de quartzo de veio. Não é conhecido ou imaginável qualquer processo geológico capaz de considerar que os materiais dessa metabrecha sofreram tranporte superior a alguns metros ou poucas dezenas de metros e, sendo assim, também os seus diamantes. Ademais, considerar a metabrecha em apreço como o retrabalhamento de vent breccia é substanciado não apenas nas suas características e na mineralização de diamantes, mas também pela semelhança com depósitos de hidrovulcanismo (conseqüência da interação do magma em ascenção com as águas contidas nos sedimentos encaixantes) descritos por Smith \& Lorenz (1989, in Mitchell, op. cit.) para o lamproíto de Ellendale (Austrália). A formação de crateras do tipo maar é denunciada pela geometria e extensão dos depósitos do Membro Campo Sampaio (Facies Lacustre Superior no sentido de Almeida Abreu 1993), ou seja, espessuras de poucas dezenas de metros e ocupando áreas localizadas na escala de algumas centenas de $m$ a superfícies da ordem de $5 \mathrm{~km}$, sendo a maioria dos (senão todos os) pelitos desses domínios o retrabalhamento intempérico e sedimentar dos depósitos de lappilli e cinzas vulcânicas. Como o vulcanismo ocorreu na borda de calhas do rifte, 


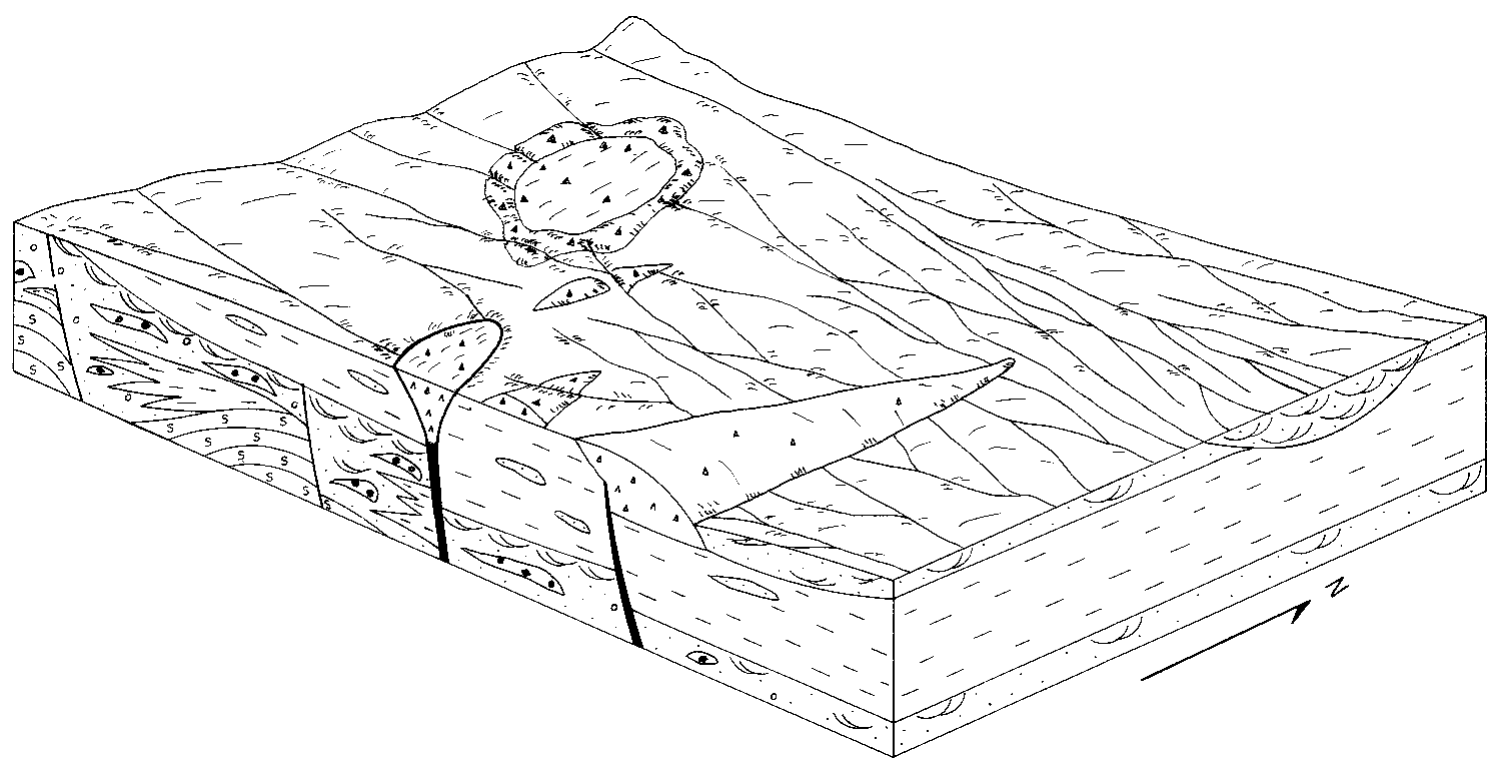

Figura 5: Bloco-diagrama esquemático exibindo o desenvolvimento dos depósitos piroclásticos do Membro Campo Sampaio com o retrabalhamento sedimentar associado. Legenda: ver Fig. 4.

Figure 5: Schematic block diagram showing the development of pyroclastic deposits with associated synsedimentary reworking of the Campo Sampaio Member. Legend: as in Fig. 4.

a reativação localizada de falhas promoveu a incisão fluvial e remoção parcial das crateras tipo maar, modificando portanto, em maior ou menor grau, as feições das mesmas.

Espetaculares são 2 apófises desse vulcanismo expostas em barranco da extremidade ocidental da Lavra de Caldeirões (Foto 7). Os corpos mostram mergulhos fortes, cortam o acamamento obliquamente e exibem espessuras decimétricas. Sua matriz micácea, parcial ou totalmente caolinizada, envolve fragmentos angulosos de metarenitos dispersos (as vezes de cor rosada ou vermelha), além de alguns seixos arrendondados de quartzo. Sua feição explosiva ressalta-se no topo de afloramento (Foto 7), via espessamento e segmentação do veio. Esse caráter explosivo do vulcanismo é demonstrado também pelos fragmentos e seixos achados no seio das apófises que, indubitavelmente, são provenientes da erosão das encaixantes devido ao aumento de volume do magma em ascenção provocado pela hidratação a partir dos sedimentos e rochas sedimentares encaixantes.

A preservação dos depósitos do Membro Campo Sampaio foi permitida especialmente devido ao seu recobrimento quase imediato pelos sedimentos arenosos da Formação Galho do Miguel. Conforme mencionado anteriormente, a instalação das unidades deste membro ocorreu na fase tardia da tectônica extensional que desenvolveu e controlou os espaços da sedimentação e o aporte de sedimentos (além do vulcanismo associado) das calhas e províncias sedimentares da faixa medianacentral da Serra do Espinhaço Meridional. A migração da atividade tectônica para domínios adjacentes orientais liberou as calhas da faixa mencionada para um regime passivo e permitindo, assim, o seu completo assoreamento pela progradação, rumo a $\mathrm{E}$, dos sedimentos eólicos daquela formação.

Conforme Almeida Abreu (1993) e Almeida Abreu \& Pflug (1994), o abandono da atividade tectônica distensiva nas calhas sedimentares (devido a sua migração progressiva para domínios contíguos orientais) permitiu, invariavelmente, o assoreamento dessas calhas por volumosos sedimentos eólicos da Formação Galho do Miguel.

Contudo, deve ser ressaltado que esses sedimentos eólicos da formação mencionada não traduzem condições climáticas áridas ou semi-áridas, sendo consequiência, isto sim, de ambiente paleoclimático específico versus a ausência de cobertura vegetal sobre as áreas continentais, ou seja, condições paleoclimáticas muito úmidas e de notável eficiência intempérica. Isto seria devido, provavelmente, às elevadas pressões de C0 atmosférico, aliada à efetiva segregação dos sedimentos exclusivamente de acordo com a competência dos agentes de transporte do ambiente.

Os domínios periglaciais pleistocênicos podem arremedar essas condições, visto que são efetivamente úmidos e desprovidos de cobertura vegetal levando a efetiva segregação dos sedimentos expostos ao transporte aéreo ou subaéreo. A exemplo, os volumosos sedimentos arenosos do Athabasca braid-delta system do Canadá onde cerca de $70 \mathrm{~km}$ de areias foram espalhadas numa superfície de $4000 \mathrm{~km}$ em período de tempo tão curto como 1.700 anos, imediatamente após o recuo da Laurentide ice-sheet (Rhine \& Smith 1988).

\section{OS REGISTROS DAS ÁREAS FONTES FORNECIDOS PELOS DIAMANTES.}

Desde 1990 o geólogo Marcos Borghetti Hartmann compra diamantes para a CINDAM (empresa brasileira 


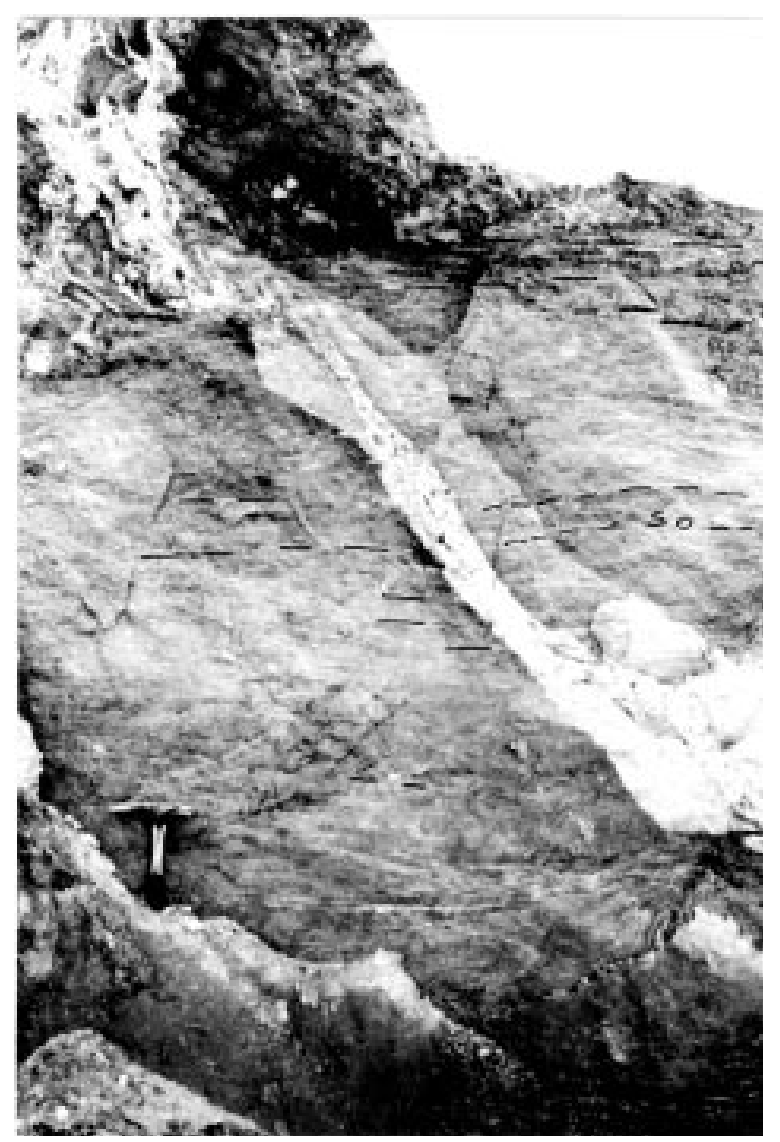

Foto 7: Apófise (veio) de rocha ígnea relacionada a vulcanismo explosivo (explicação no texto).

Photo 7: Vein like apophysis of igneous rock related to explosive volcanism.

de lapidação e exportação de diamantes). Nesses 6 anos o Sr. M. B. Hartmann (comun. oral) comprou cerca de 200 mil quilates (ct) de diamantes oriundos da região de Diamantina (incluindo diamantes de drenagens das 3 bacias hidrográficas da Serra do Espinhaço Meridional e de rochas rudíticas da Formação SopaBrumadinho). A análise destes diamantes mostra, claramente, que as gemas reúnem caraterísticas peculiares de acordo com a sua procedência, indicando a província de origem, conforme sumarizado a seguir:

\section{Província de Campo Sampaio / São João da Chapada}

Os diamantes desta província são "porosos" (mostram cavidades alveolares), geralmente esverdeados, frequentemente amarelos ou castanhos e apenas cerca de $15 \%$ são brancos (translúcidos). As cores H e I (quanto à cor, os diamantes são classificados - em ordem decrescente de qualidade - de D a L) são, em geral, dominantes embora cerca de $30 \%$ dos diamantes dos lotes produzidos nesta região sejam do tipo industrial.

\section{Província de Sopa / Guinda}

Nesta província predominam diamantes de tamanhos médios $3 \times 1$ ou maior ( $3 \times 1$, 10x1, etc.,

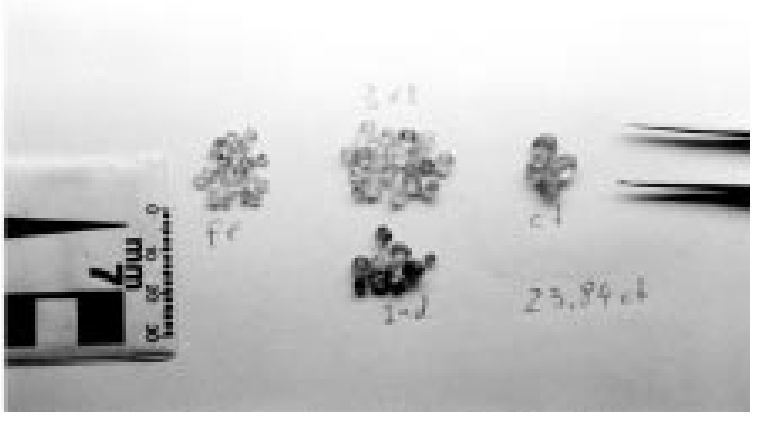

Foto 8: Pequeno lote de diamantes oriundo de afluentes da margem direita do Rio Paraúna. $\boldsymbol{F F}=$ fazenda fina; Ind = tipo industrial; $\boldsymbol{c t}=$ pedras superiores a 1 quilate. (Peso total. 23, 84 quilates).

Photo 8: Small lot of diamonds from right tributaries of the Rio Paraúna. FF = very small stones $(<10$ points); $3 x \boldsymbol{1}=3$ stones weighing 1 ct; Ind = industrial quality; $\boldsymbol{c t}=$ stones bigger than 1 carat (total weight of the lot: 23,84 ct).

significa o número de diamantes para compor $1 \mathrm{ct}$ ) e, embora mostrem-se inferiores aos da Província de Datas (especialmente nas formas) são de boa qualidade e as quantidades do tipo industrial são inferiores a $10 \%$.

\section{Província de Datas}

Esta província produz, em geral, os melhores diamantes da região mostrando cor $\mathrm{H}$ ou melhor. Predominam octaedros em tamanhos $3 \times 1$ ou maior, frequentemente com pedras acima de $1 \mathrm{ct}$. A quantidade de diamantes industriais produzida é desprezivel.

\section{Província de Extração}

É a província da região que produz os maiores diamantes, seja na média, seja como pedras individuais, haja visto que o "Paulo de Frontim" o maior diamante da Serra do Espinhaço oficialmente conhecido (com $50 \mathrm{ct}$ ), foi encontrado na Lavra da Boa Vista. Deve ser destacado que a Lavra do Cavalo Morto produz diamantes de qualidade tão boa como os de Datas.

Pelo exposto, e ressaltando mais uma vez que um comprador experiente de diamantes da região consegue individualizar de um conjunto, as gemas das respectivas províncias, pode-se concluir o seguinte:

1) O caráter particular das gemas de cada província proíbe que as mesmas sejam oriundas de uma fonte tão distante como o Cráton do São Francisco conforme proposto por Pflug (1965), Karfunkel et al. (1984), entre outros, visto que, nesta situação, a tendência seria de homogeneização e não de segregação dos diamantes em conjuntos distintos.

2) Como o fluxo sedimentar é claramente de $W$ para E, e considerando que a Província de Extração situa-se a cerca de $22 \mathrm{Km}$ a ESE da Província de Sopa-Guinda, no caso de uma fonte comum situada no Cráton do São Francisco os diamantes das lavras de Extração seriam, em média, menores do que os das lavras de Sopa- 
Guinda, quando o que se observa é exatamente o inverso.

Ademais, outras informações genéricas são tão (ou mais) reveladoras de que os diamantes são oriundos de fonte intrínseca da respectiva província, conforme descritas a seguir:

1) Os diamantes dos cascalhos dos rios e córregos da região são em média, rigorosamente menores do que as gemas dos metaconglomerados evidenciando distanciamento da área fonte o que não ocorre, conforme mencionado anteriormente, nas províncias de metaconglomerados mesmo quando em seção paralela ao fluxo sedimentar.

2) Os diamantes das drenagens da região mostram, sistematicamente, evidências de retrabalhamento clástico como quebras e fissuras nas arestas e/ou faces (as conhecidas "unhas" e "jaças"), além de mostrarem superfícies mais foscas e porosas e mesmo porções parcial- ou totalmente arredondados. Nesse sentido, os diamantes, explotados diretamente dos metaconglomerados e metabrecha estão, em regra, "intactos" evidenciando uma área fonte muito próxima.

3) Os chips nos lotes de diamantes, produzidos nas rochas da Formação Sopa-Brumadinho são raros ou ausentes, enquanto nos lotes produzidos nos rios e córregos são muito comuns (chips são lascas de diamantes produzidas pela quebra das gemas durante o transporte e retrabalhamento sedimentar).

\section{KIMBERLITOS OU LAMPROÍTOS?}

Sob o ponto de vista petrográfico e litogeoquímico a identificação da rocha-mãe dos diamantes da Província de Sopa - Guinda (e por extensão da Serra do Espinhaço) está prejudicada, haja visto o avançado estado de alteração em que se encontram. Seu caráter ultrapotássico e elevado conteúdo de $\mathrm{Mg}$ mostra-se preservado localmente como, por exemplo, nos xistos verdes das Lavra do Damásio (Knauer 1990).

Por outro lado, um profundo perfil de alteração na seção mais superior bé característico dos afloramentos de kimberlitos que podem atingir espessuras de 60 a 100 metros (incluindo o yellow ground e o blue ground) conforme observado em kimberlitos da África do Sul (Bardet 1973: 46 - 47). Mesmo na Sibéria os primeiros 5 a 10 metros dos kimberlitos aflorantes mostram-se profundamente alterados, embora esses green grounds sejam considerados um yellow ground fóssil de idade mesozóica (Bardet, op. cit.).

Deve ser destacado que, embora as rochas em apreço mostrem também expressiva alteração recente sobre quase todos os afloramentos, a alteração proterozóica (sin-sedimentar) foi profunda e generalizada quando todos os minerais originais foram virtualmente decompostos. Após o metamorfismo, a rocha foi transformada em sericita-filito com porções localizadas mais ou menos ricas em clorita, podendo aparecer, como minerais acessórios, zircão, óxidos de titânio, quartzo e óxidos de ferro. Vazios de minerais decompostos (box works) podem também aparecer, possivelmente deixados pela saída de magnetita ou pirita. Uma textura mosqueada é relativamente comum, evidenciando processos irregulares e descontínuos de lixiviação que pontuaram o perfil de alteração com manchas de caolinização. As bandas milimétricas a centimétricas de óxidos de ferro, assim como concreções ferruginosas, são ótimos indicadores dos processos de decomposição e oxidação sin-sedimentar impostos sobre as rochas ígneas diamantíferas abordadas e, portanto, invariavelmente mostram-se segmentadas (oblíqua- ou ortogonalmente) pela xistosidade, muitas vezes transpondo parcial- ou totalmente essas bandas e concreções.

Assim, rocha fresca desses diques deve ser alcançada provavelmente a dezenas de metros de profundidade da atual superfície de exposição.

Sob o ponto de vista da ambiência geotectônica versus as carcterísticas dos diamantes encontrados na região, as informações são conflitantes no sentido de definir as rochas ígneas diamantíferas da Serra do Espinhaço Merdional como kimberlitos ou lamproítos.

Tanto Bardet (1973: 119) como Mitchell (1993) - e referências por ele citadas - são unânimes em admitir que kimberlitos são rochas típicas de plataformas estáveis (crátons arqueanos), embora Mitchell (op. cit.) admita a presença de kimberlitos estéreis em faixas dobradas ou em domínios cratônicos submetidos a processos mal sucedidos de rifteamento (neste caso podem ser diamantíferos).

Por outro lado, os lamproítos podem aparecer em diferentes ambientes geotectônicos, independente de serem mineralizados ou não em diamantes, mas, em regra, produzem diamantes proporcionalmente pequenos e com quantidades significativas de diamantes "tipo indústria" (Bardet 1974: 208, 221; Mitchell 1993). Neste particular deve ser lembrado que os metakimberlitos definidos Bardet (1973, 1974, 1977) no Gabão (Mitzic) e Costa do Marfim (Seguela) são, na realidade, lamproítos (Mitchell, op. cit.).

Pelo exposto, e considerando que as rochas ígneas diamantíferas da Serra do Espinhaço são de magmatismo sin-rifte e que os diamantes são proporcionalmente pequenos mas com pequenas quantidades do "tipo indústria" (abaixo de 10\% nos metaconglomerados) torna-se dificil definir, no momento, qual a classe dessas rochas.

\section{CONSIDERAÇÕES FINAIS}

As propostas deste trabalho vem ao encontro de observações antigas quanto às rochas primárias dos diamantes da Serra do Espinhaço (cf. Moraes 1934, Moraes e Guimarães 1929) ou seus agentes mineralizadores (ver síntese das discussões em Bardet 1977: 95 e Almeida Abreu \& Munhóz 1983).

No que diz respeito ao fenômeno magmático, considerando as suas relações temporais e espaciais, vem reforçar que o Rifte Espinhaço foi termalmente 


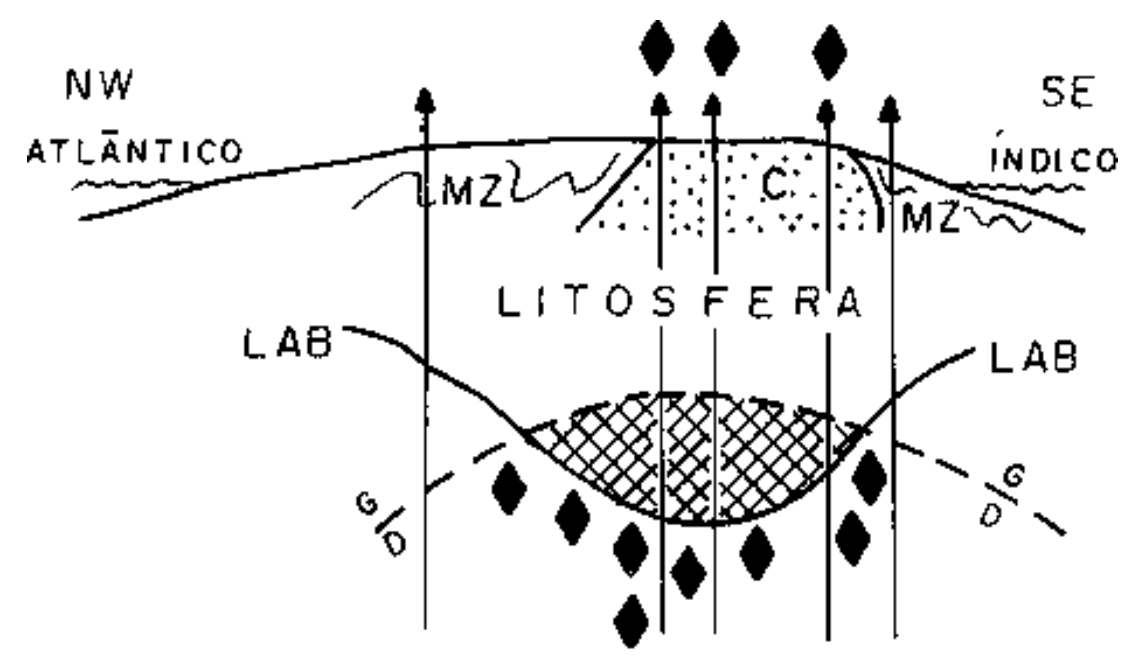

ASTENOSFERA

Figura 6: Modelo apresentado por Mitchell (1993, concebido em seção no Cráton do Kaapvaal, África do Sul) para ilustrar o domínio diamantífero litosférico (hachuriado) e sublitosférico (losângulos) e explicar as razões da não mineralização em diamantes dos kimberlitos que penetram as zonas móveis (MZ) adjacentes aos crátons

(C). LAB: limite litosfera-astenosfera; $G$ / D: curva invariante grafita / diamante.

Figure 6: Model proposed by Mitchell (1993, idealized in a section of the Kapvaal Craton, South Africa) to illustrate the lithospheric diamond- bearing domain (cross hatched) and the sublithospheric domain (rhombus) as well as to explain the reasons why non-diamondiferous kimberlites penetrate mobile zones (MZ) adjacent to

the cratons (C). LAB: lithosphere-astenosphere boundary; G/D: graphite-diamond univariant curve.

controlado conforme proposto por Almeida Abreu (1993, 1995).

Segundo modelos recentes, baseados especialmente em estudos isotópicos e litogeoquímicos, os diamantes contidos nos lamproítos tem origem relacionada a ultrametamorfismo de sedimentos associados à subducção de segmentos de crosta oceânica (Mitchell 1993). Neste particular, sob o prisma da distribuição ultra-regional dos diamantes da Serra do Espinhaço desde o E do Quadrilátero Ferrífero até o N da Chapada Diamantina na Bahia - onde diferentes entidades orogenéticas arqueanas e/ou paleoproterozóicas servem de substrato à cobertura mesoproterozóica que encaixa as rochas diamantíferas, deve-se admitir que, senão todos, pelos menos a maioria desses orógenos antigos representariam a colisão de blocos crustais invertendo bacias oceânicas.

Por outro lado, a eventual comprovação de que as rochas magmáticas diamantíferas da Serra do Espinhaço são de fato kimberlitos leva ao modelo da delaminação litosférica com a formação de plumas astenosféricas no domínio da tectosfera que seria ligeiramente deslocada até o domínio externo adjacente da área cratônica e permitindo assim magmatismo kimberlítico em riftes que bordejam crátons arqueanos (compare as Figs. 2 e 6).

Sob o ponto de vista econômico, somente uma pesquisa específica pode comprovar a mineralização em teores que justifiquem a exploração sistemática dos mesmos, contudo, a expectativa das rochas em questão serem, de fato, kimberlitos seria mais positivo em vista da manutenção dos teores com a profundidade - salvo raras exceções - enquanto os lamproítos são muito ricos, em geral, apenas nas porções piroclásticas das chaminés (Mitchell 1993).

\section{AGRADECIMENTOS}

Expresso meus agradecimentos ao $\mathrm{CNPq}$ pelo suporte financeiro permanente aos programas do Centro de Geologia Eschwege (Processos 42.0003/932,40.0366/94-0 e 40.0009/95-1) que permitem o constante refinamento dos dados geológicos da região de Diamantina, assim como à FAPEMIG pelo financiamento de pesquisa voltada para a Análise da Bacia Espinhaço (Processo CEX - 1065 / 94). O incentivo e discussões mantidas pelos colegas L. G. Knauer, F. E. Renger e A. G. Costa foram muito valiosas para o desenvolvimento deste trabalho. Agradecimento especial é devido também ao geólogo Marcos B. Hartmann pelas informações sobre os diamantes da região bem como pela permissão de fotografar o lote de diamantes da foto 8 . Os funcionários do C. G. Eschwege devem ser lembrados pelo apoio permanente às nossa atividades de pesquisa.

\section{REFERÊNCIAS BIBLIOGRÁFICAS}

ALMEIDA ABREU, P. A. (1993) - A evolução geodinâmica da Serra do Espinhaço Meridional, Minas Gerais, Brasil. Diss. Doutorado. Univ. Freiburg, Alemanha, 150 p.(inédito).

ALMEIDA ABREU, P. A. (1995) - Supergrupo Espinhaço: o rifte, a bacia e o orógeno. Geonomos, 3: 1 - 18. 
ALMEIDA ABREU, P. A. \& MUNHÓZ, D. T. V. (1983) - A reconstituição paleogeográfica e o estudos dos minerais pesados como indicativos de áreas fontes primárias dos diamantes da Serra do Espinhaço, Minas Gerais.In: SIMP. GEOL. MINAS GERAIS, 2, Belo Horizonte, 1983. Anais ...Belo Horizonte, SBG/MG, Bol. 3, p. 219 - 234.

ALMEIDA ABREU, P. A. \& PFLUG, R. (1994) - The geodynamic evolution of the southern Serra do Espinhaço, Minas Gerais, Brasil. Zbl. Geol. Paläont., H 1/2: 21 - 44.

ANDERSON, D. L. (1982) - Hotspots, polar wander, Mesozoic convection and the geoid.- Nature, 297: 391 - 393.

BARBOSA, O. (1951) - Contribuição à origem do diamante em Diamantina, Estado de Minas Gerais. DNPM, - DGM, Bol. 136, $36 \mathrm{p}$.

BARDET, M. G. (1973) - Géologie du Diamant - Première Partie: Généralités. B.R.G.M., Mem. 83, 235 p., Paris.

BARDET, M. G. (1974) - Géologie du Diamant - Deuxième Partie: Gisement de Diamant d'Afrique. B.R.G.M., Mem. 83, 229 p., Paris.

BARDET, M. G. (1977) - Géologie du Diamant - Troisième Partie: Gisements de Diamants d'Asie, d'Amérique, d'Europe et d'Australasie. B.R.G.M., Mem. 83, 169 p., Paris.

BIRD, P. (1979) - Continental delamination and the Colorado Plateau. J. Geophys. Res., 84: 7561 - 7571

BOYER, S. E. \& ELLIOT, D. (1982) - Thrust systems. Amer. Assoc. Petrol. Geol. Bull., 66: 1196 - 1230.

BUCK, W. R. (1988) - Flexural rotation of normal faults. Tectonics, 7: $959-973$

CORRENS, C. W. (1932) - Über die Diamantenlagerstätten des Hochlandes von Diamantina, Minas Geraes, Brasilien. Zeitsch. Prakt. Geol., 10: 161 - 168, 177 - 181

DAVIS, G. H. (1983) - Shear-zone model for the origin of metamorphic core complexes. Geology, 11: 342 - 347.

ENGLAND, P. (1983) - Constraints on extension of continental lithosphere. J. Geophys. Res., 88: 1145 - 1152.

ENGLAND, P. \& McKENZIE, D. (1982) - A thin viscous sheet model for continental deformation. Geophys. J. R. Astr. Soc., 70: 295 - 321.

FLEISCHER, R. (1995) - Prospecção e economia do diamante da Serra do Espinhaço. Geonomos, 3: 27 - 30

FOGAÇA, A.C. C. \& ALMEIDA ABREU, P. A. (1982) - Depósitos de planícies de marés na Formação Sopa-Brumadinho (Proterzóico Inferior) Cordilheira do Espinhaço, Estado de Minas Gerais, Brasil. In: CONGR. LATINOAMER. GEOL., 5, Buenos Aires, 1982. Actas... Buenos Aires, v. 2, p. 373 388

GROTZINGER, J. P. (1989) - Facies and evolution of Precambrian carbonate depositional systems: Emergence of the modern platform archetype. Soc. Econ. Petrol. Miner., Sp. Publ. 44: 79 $-106$.

GURNIS, M. (1988) - Large-scale mantle convection and the aggregation and dispersal of supercontinent. Nature, 332: 695 $-699$

HEWARD, A. P. (1978) - Alluvial fan sequence and megasequence models: With examples from Westphalian D - Stephanian B coalfields, northern Spain. Can. Soc. Petrol. Geol., Mem. 5, p. $669-701$.

HOFFMANN, C. (1983) - The Costa Sena Group - An Early Proterozoic supracrustal sucession and the evolution of the southern Serra do Espinhaço, Minas Gerais, Brazil. Zbl. Geol. Paläont., 3/4: 446 - 458.

HOUSEMAN, G. \& ENGLAND, P. (1986) - A dynamical model of lithosphere extension and sedimentary basin formation. J. Geophys. Res. 91: 719 - 729.

HYNES, A. (1982) - Stability of the oceanic tectosphere - a model for Early Proterozoic intercratonic orogen. Earth Plan. Sci. Lett., 61: $333-345$.

KARFUNKEL, J.; CHAVES, M.L.S.C.; SVISERO, D..P. \& MEYER, H.O.A. (1994): Diamao0nds from Minas Gerais, Brazil: An update on sources, origin, and production. Internat. Geol. Rev.36:1019 - 1022

KASTINGS, J. F. (1989) - Long term stability of the Earth's climate. Palaeogeogr., Palaeoclim., Palaeoec., 75: 83 - 95.

KNAUER, L. G. (1990) - Evolução geológica do Precambriano da porção centro-leste da Serra do Espinhaço Meridional e metalogênese associada. Diss. Mestrado. Campinas. UNICAMP, Dpto. Geoc., 298 p. (inédito).
KNAUER, L. G. \& SCHRANK, A. (1993) - A origem dos filitos hematíticos da Serra do Espinhaço Meridional, Minas Gerais. Geonomos, 1: 33 - 38 .

LEEDER, M. R.; ORT, D. M. \& COOLIER, R. (1988) Development of fluvial and fan deltas in neotectonic extensional settings: Implications for the interpretations of basin fills. In: NEMEC, W. \& STEEL, R. J. (ed.), 1988. Fan Deltas: Sedimentology and Tectonic Settings. London (Blackie) p. 173 $-185$.

MACHADO, N.; SCHRANK, A.; ABREU, F. R. de; KNAUER, L. G. \& ALMEIDA ABREU, P. A. (1989) - Resultados preliminares da geocronologia $\mathrm{U} / \mathrm{Pb}$ na Serra do Espinhaço Meridional. In: SIMP. GEOL. MINAS GERAIS, 5, Belo Horizonte, 1989. Anais ... Belo Horizonte, SBG/MG, Bol. 10, p. $171-174$.

MARUYAMA, S. (1994) - Plume tectonics. J. Geol. Soc. Japan, 100: 24 - 49.

MITCHELL, R, H, (1993) - Kimberlites and lamproites: Primary sources of diamond. In: SHEANAN, P. A. \& CHERRY, M. E. (eds.), 1993. Ore Deposits Models, vol II. Geosci. Can. Reprint Series 6, p. 13 - 28

MORAES, L. J. de (1934) - Depósitos diamantíferos do norte de Minas Gerais. DNPM - SFPMBol. 3, 77 p..

MORAES, L. J. de \& GUIMARÃES, D. (1929) - Estudos sobre a rocha matriz do diamante. DNPM - SGM, Rel. An. Dir. 1928 , p. $171-174$.

NANCE, D.; WORSLEY, T. R. \& MOODY, T. R. (1988) - The supercontinent cycle. Scient. Amer., July: 44 - 51.

NELSON, R. A.; PATTON, T. L. \& MORLEY, C. K. (1992) - Riftsegment interaction and its relation to hydrocarbon exploration in continental rift systems. Amer. Assoc. Petrol. Geol., Bull. 76: $1153-1169$

PFLUG, R. (1965) - A geologia da parte meridional da Serra do Espinhaço e zonas adjacentes, Minas Gerais. DNPM - DGM, Bol. 226, 55 p..

PFLUG, R. (1968) - Observações sobre a estratigrafia da Série Minas na região de Diamantina, Minas Gerais. DNPM - DGM, Not. Prelim. Est., 142; 20 p.

RETALLACK, G.; GRANDSTAFF, D. \& KIMBERLEY, M. (1984) - The promise and problems of Precambrian paleosoils. Episodes, 7: 8 - 10 .

RHINE, J. L. \& SMITH, D. G. (1988) - The Late Pleistocene Athabasca braid delta of northeastern Alberta, Canada: A periglacial glacial drainage system affected by aeolian sand supply. In: NEMEC, W. \& STEEL, R. J. (eds.), 1988. Fan Deltas: Sedimentology and Tectonic Settings. London (Blackie) p. $158-169$.

SCHÖLL, W. U. \& FOGAÇA, A. C. C. (1979) - Estratigrafia da Serra do Espinhaço na região de Diamantina. In: SIMP. GEOL. MINAS GERAIS, 1, Diamantina, 1979. Atas... Belo Horizonte, SBG/MG Bol. 1, p. 55 - 73.

SCOTT, D. L. \& ROSENDAHL, B. R. (1989) - North Viking graben: An east African perspective. Amer. Assoc. Petrol. Geol., Bull. 73: 155 - 165 .

SPENCER, J. E. (1984) - Role of tectonic denudation in warping and uplift of low-angle normal faults. Geology, 12: 95 - 98.

SVISERO, D. P. (1978) - Composição química, origem e significado geológico de inclusões minerais de diamantes do Brasil. Tese Livre Docência. IG/USP, São Paulo, 165 p. (inédito).

THOMPSON, A. B. \& ENGLAND, P. (1984) - Pressuretemperature-time paths of regional metamorphism II. Their inferences and interpretation using mineral assemblages in metamorphic rocks. J. Petrol. 25: 929 - 955.

VAIL, P. R.; MITCHUM, R. M.; TODD, R. G.; WIDMIER, J. M. THOMPSON, S.; SANGREE, J. B.; BUBB, J. N. \& HATLELID, W. G. (1977) - Seismic stratigraphy and global changes of sea level. In: CLAYTON, C. E. (ed.) 1977. Seismic Stratigraphy - Application to Hydrocarbon Exploration. Amer. Assoc. Petrol. Geol., Mem. 26, p. 49 - 212.

WALKER, R. G. (ed.) - (1979) - Facies Models. Geosci. Canada Reprint Series, 1 ( first edition), 305 p..

WERNICKE, B. (1981) - Low-angle normal faults in the Basin and Range province: Nappe tectonics in an extending orogen. Nature, 291: 645 - 647.

YIN, A. (1991) - Mechanisms for the formation of domal and basinal detachment faults: a three-dimensional analysis. J. Geophys. Res., 96: 14577 - 14594. 